\title{
تأثير التقدم التكنولوجي على الأسس والمبادئ التي تحكم القانون الدولي \\ Doi: 10.23918/ilic2021.21
}

\section{الاكتورة: سامية كرليفة.}

أستاذة محاضرة ، كلية الحقوق والعلوم السياسية، جامعة يحية كرلفة فارس، المدية، الجزائر. pr.samiadroit@gmail.com

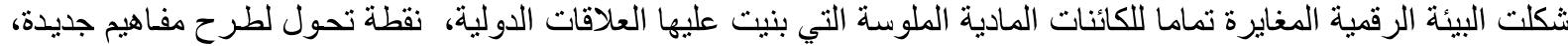

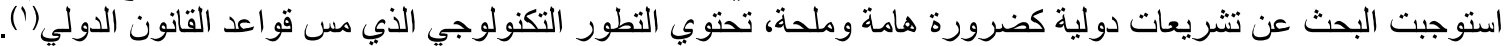

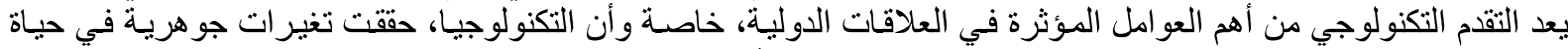

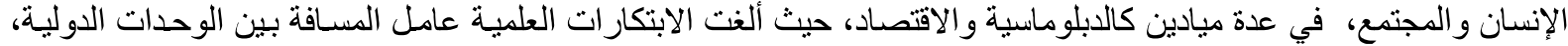

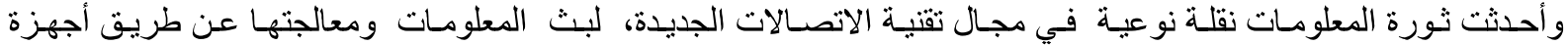
الكمبيوتر (؟). ثار جدل فقهي حول أثر التطور التكنولوجي على قواعد القانون الدولي،إذي يقر أنصار التوجه الأول أن التطورات العلمية كان لها

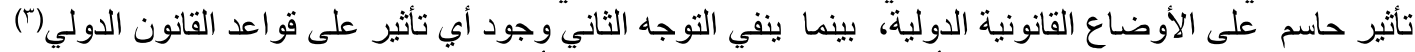

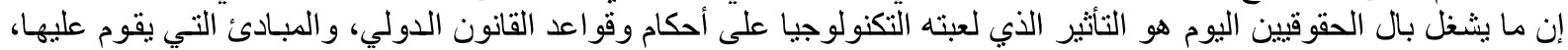

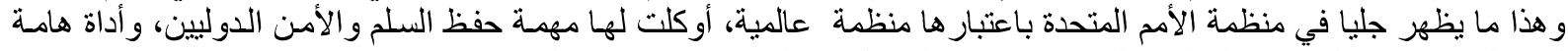

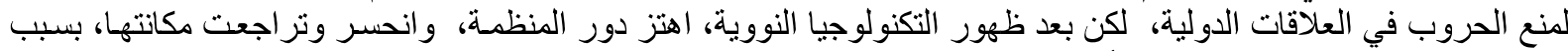

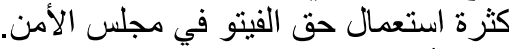

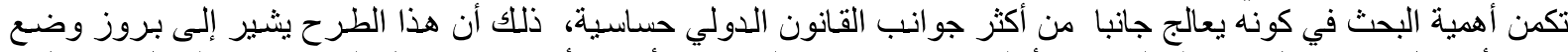

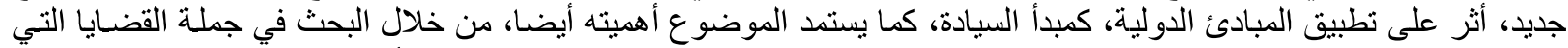

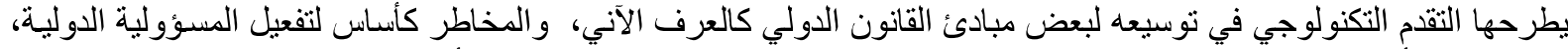

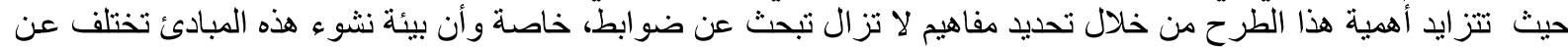

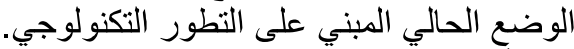

إن الأهمية البالغة التي بات يحظى بها موضوع تأثثير التقدم التكنولوجي على المبادئ والأسس التي تحكم القانون الدولي، جعل

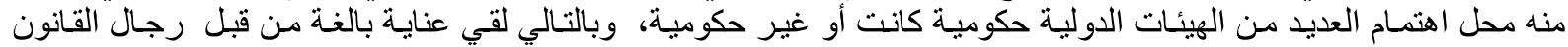

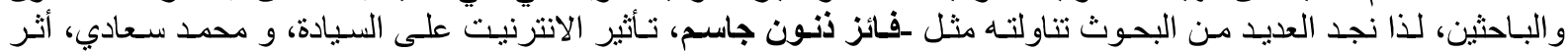

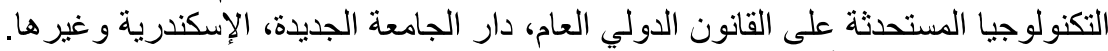

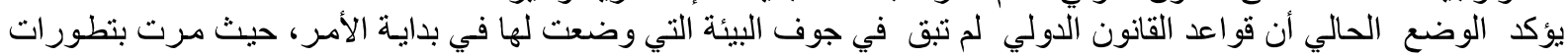

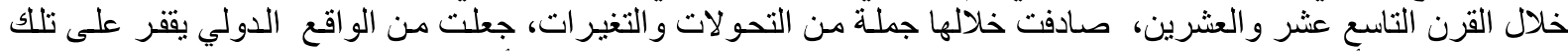

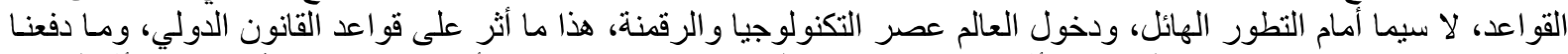

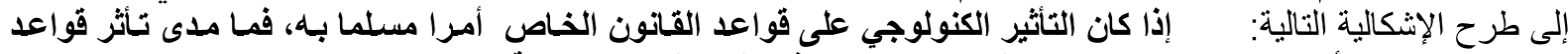

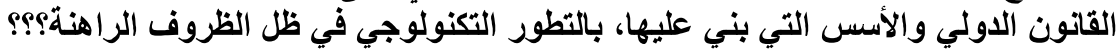

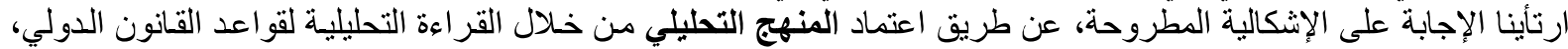

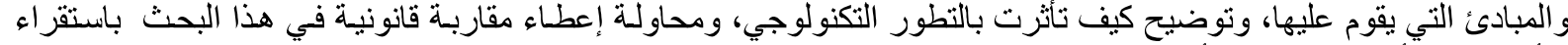

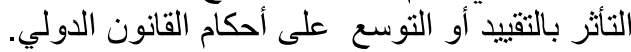

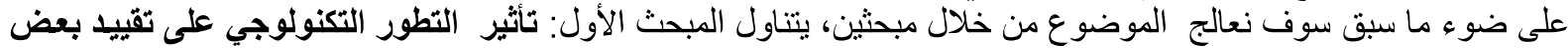

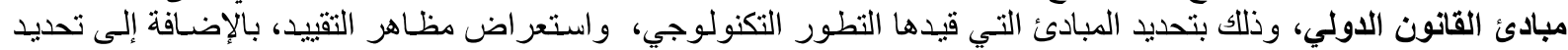

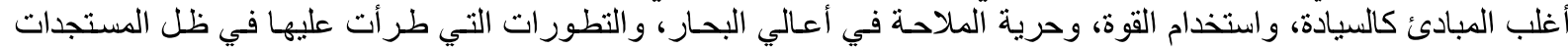

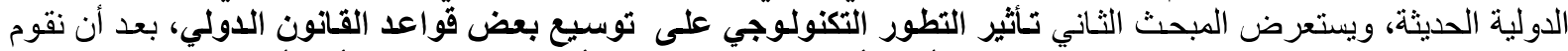

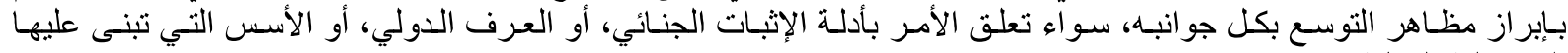

المبحث الأول: تأثير التطور التكنولوجي على تقييا بعض مبادئ القانون الدولي المسؤولية الدولية.

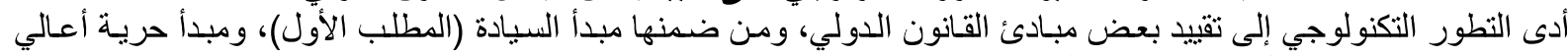

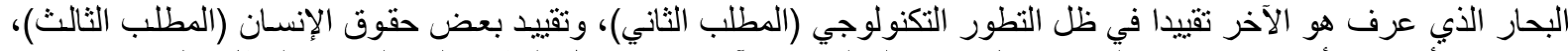
كما عرف أيضا مبدأ حرية استخدام القوة في العلاقات الدولية هو الآخر تقييدا بفعل التطور التكنولوجي (المطلب الرابع).

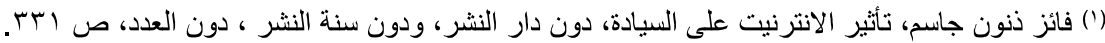

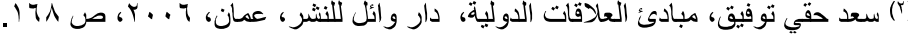

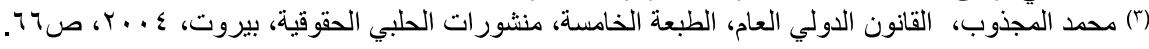


المطلب الأول: تقييا مبدأ السيادة في ظل التقدم التكنولوجي

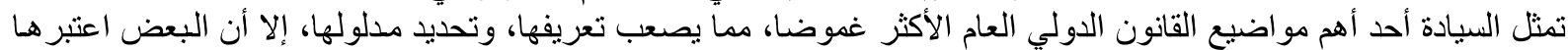

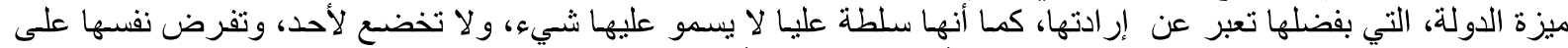

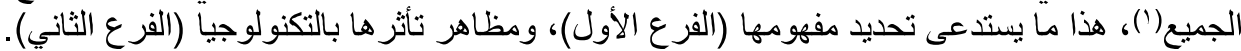

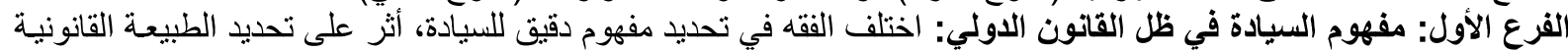

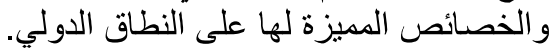

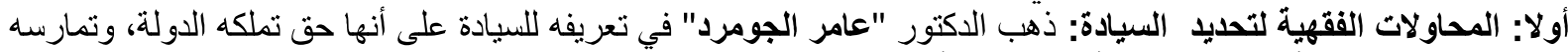

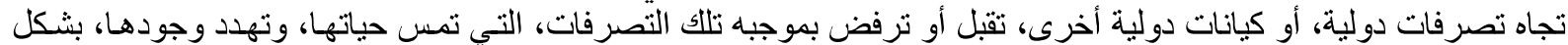

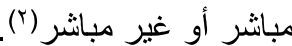

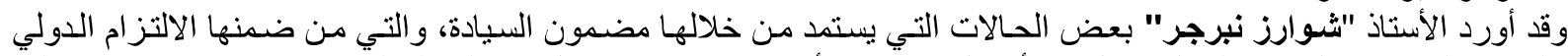

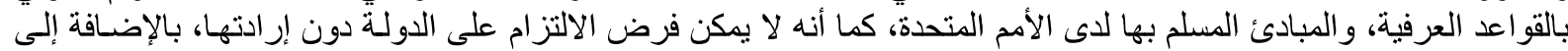

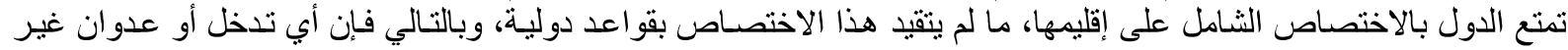

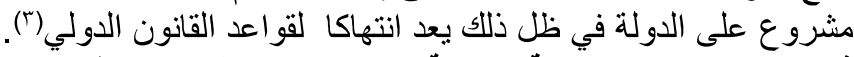

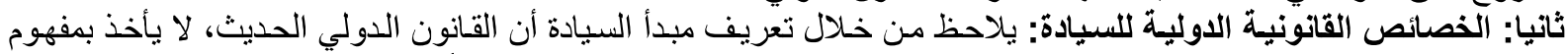

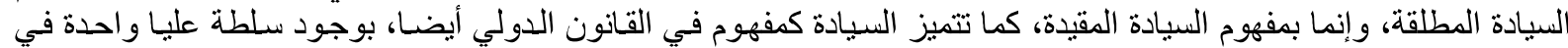

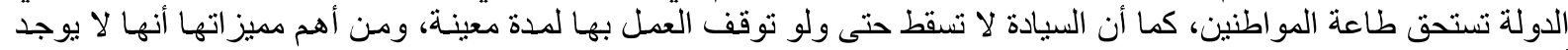

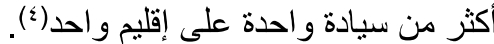

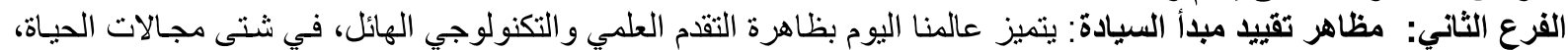

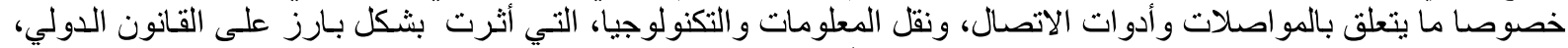

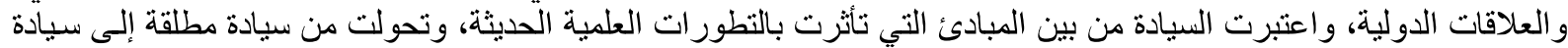

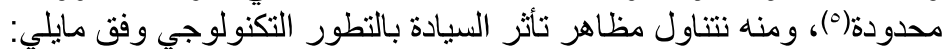

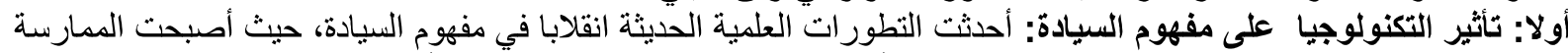

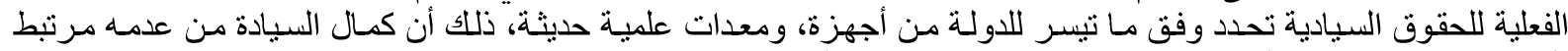

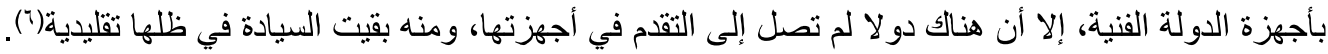

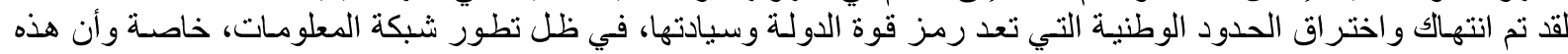

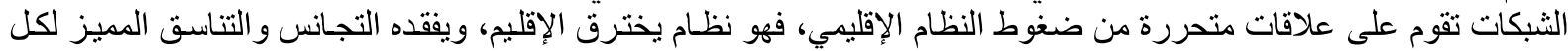

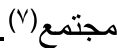

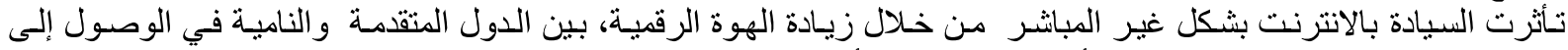

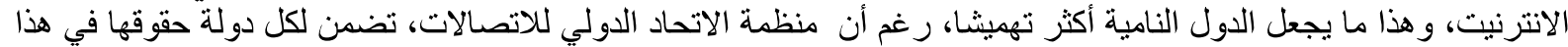

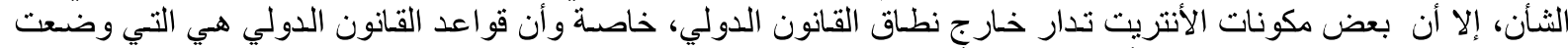

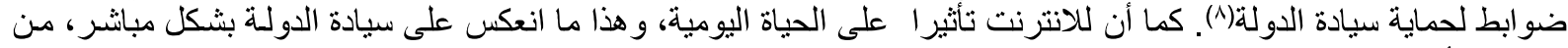

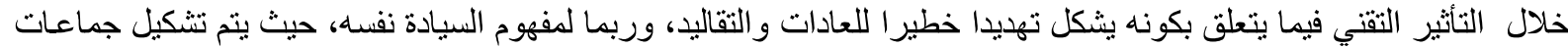

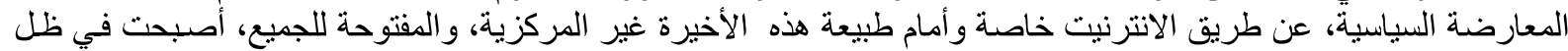

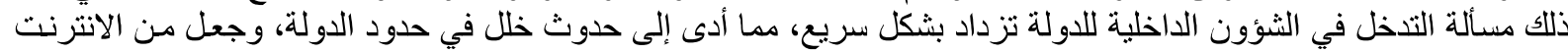

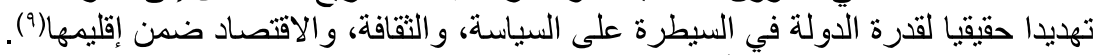

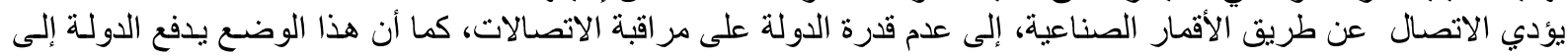

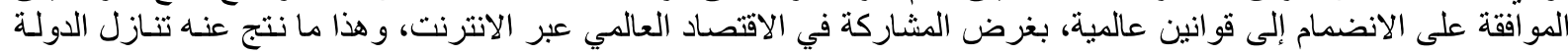

عن جزء من السيادة الوطنية(·' (')

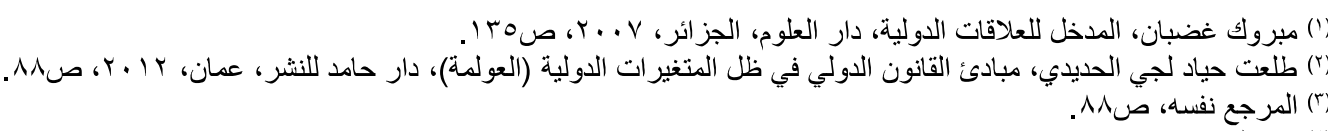

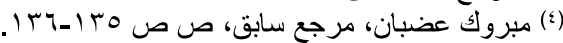

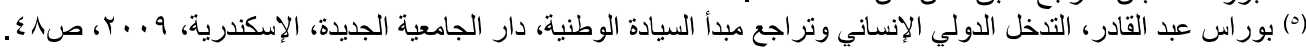

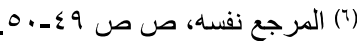

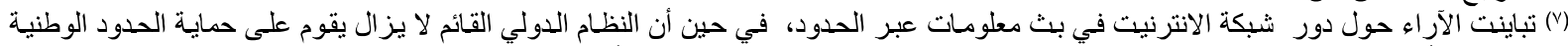

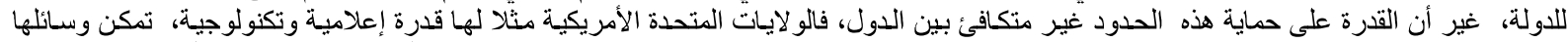

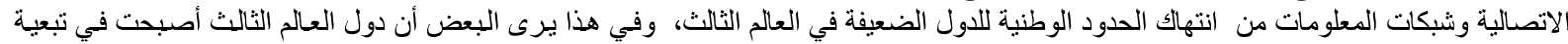

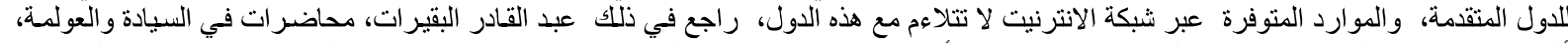

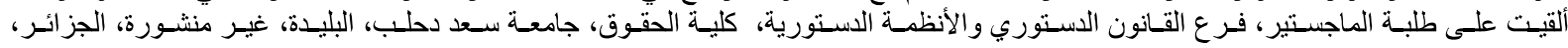

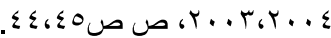

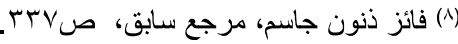

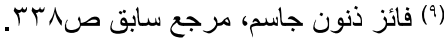

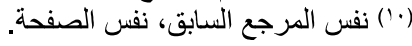


أصبحت المجالات الأساسية للسيادة بفعل التقدم التكنولوجي مفتوحة ومستباحة، ذلك أن الأقوى تكنولوجيا بتمتع بقدرته فائقة على الكي

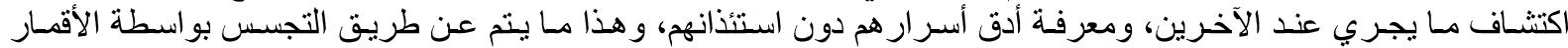

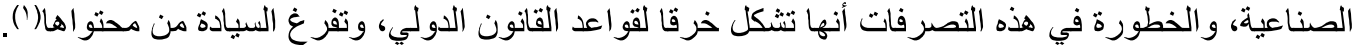

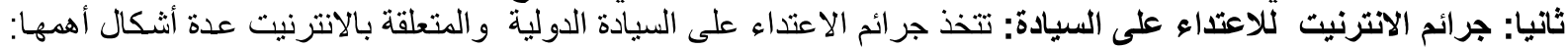

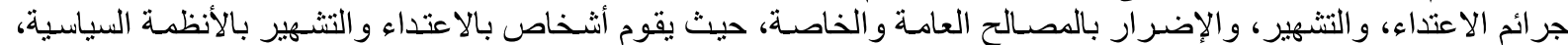

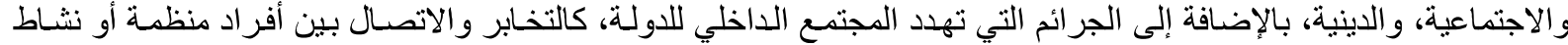

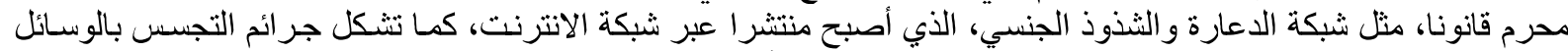

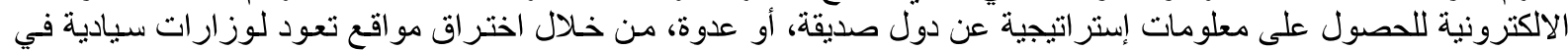

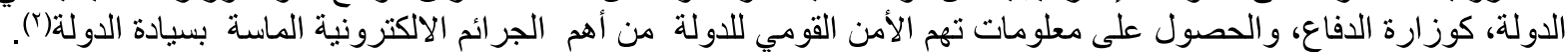

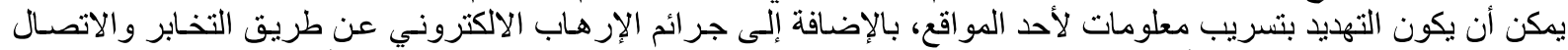

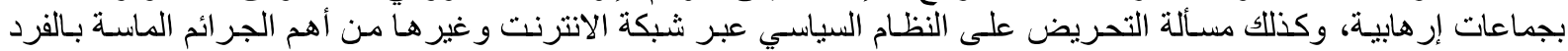

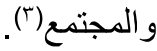

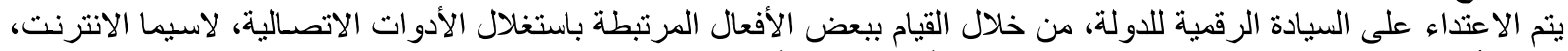

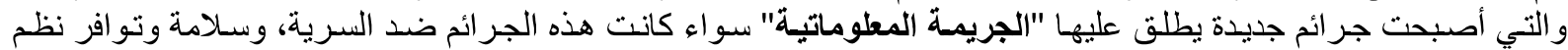

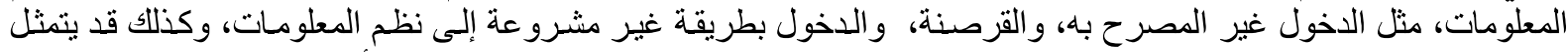

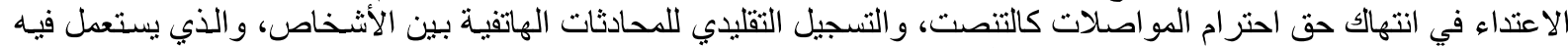

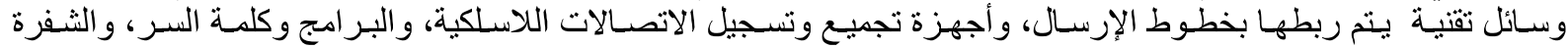

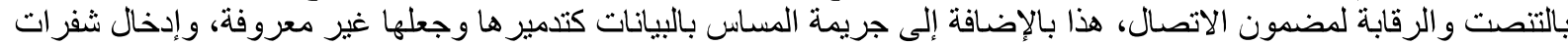

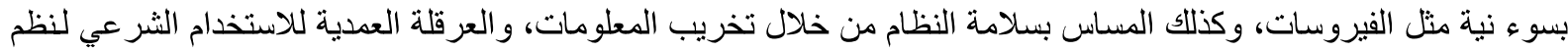

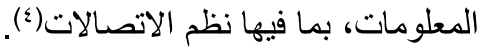

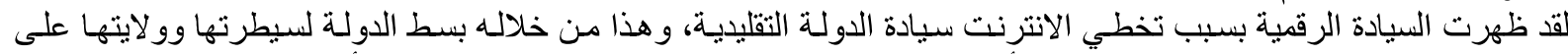

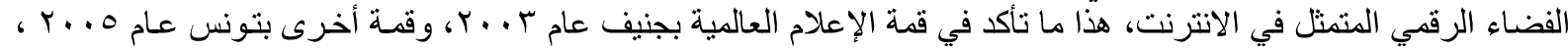

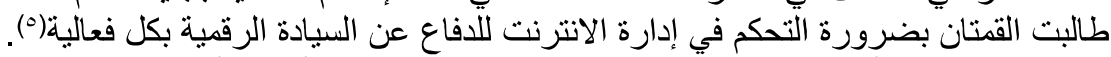

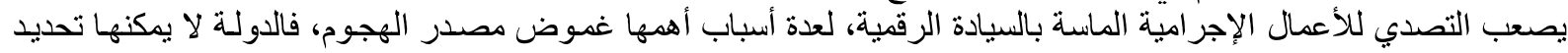

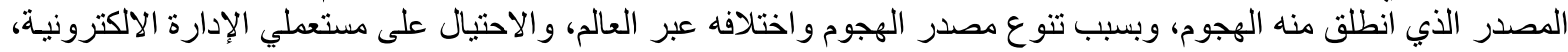

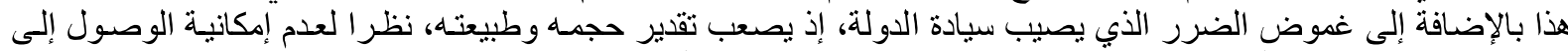

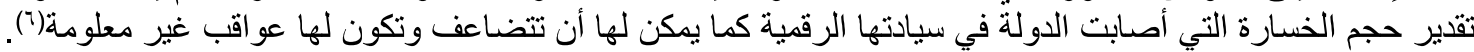

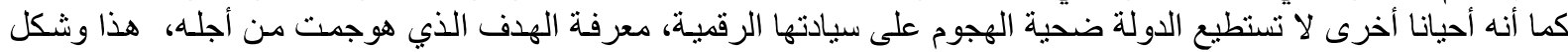

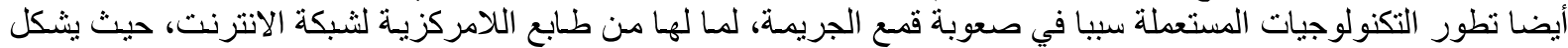

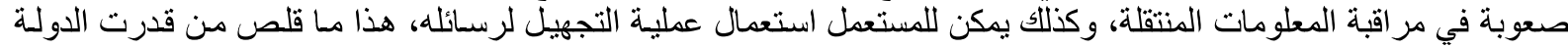

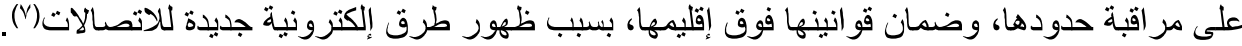

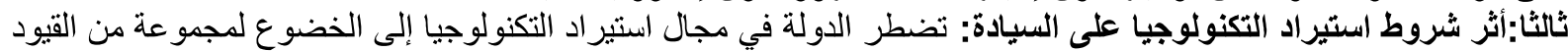

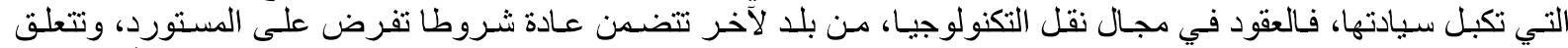

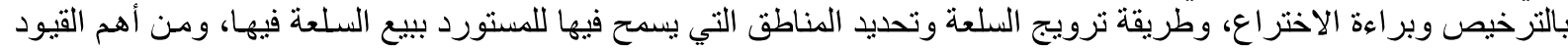

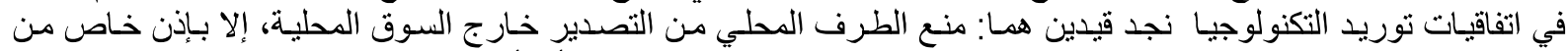

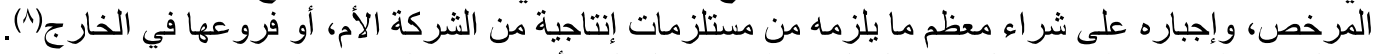

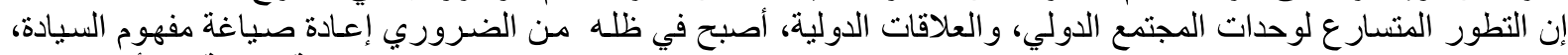

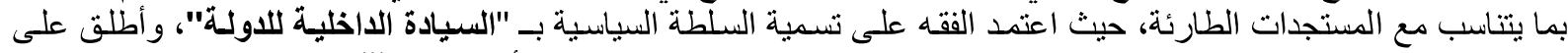

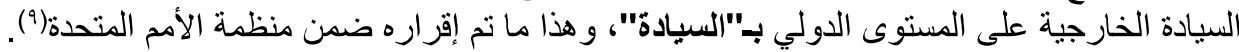

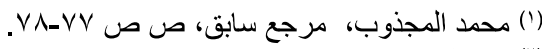

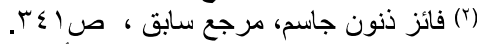

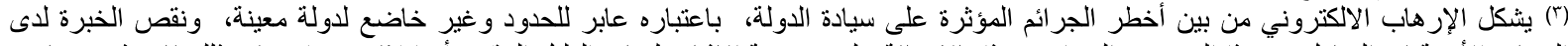

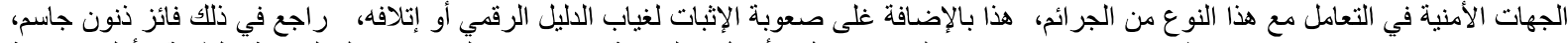

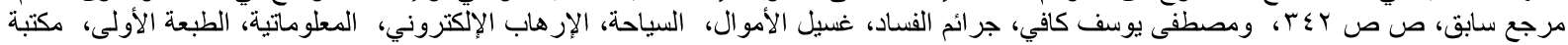

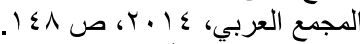

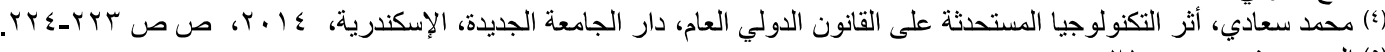

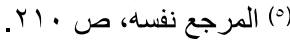

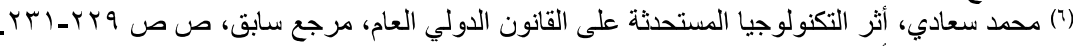

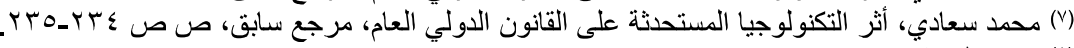

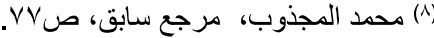

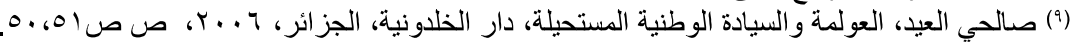




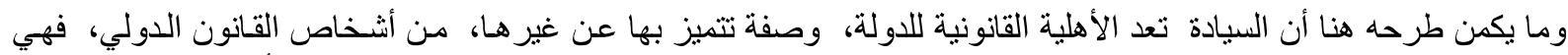

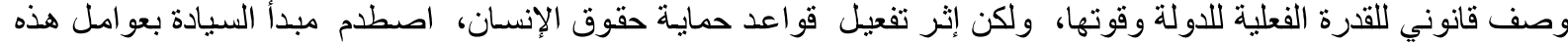

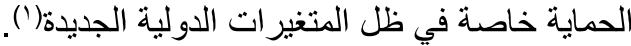

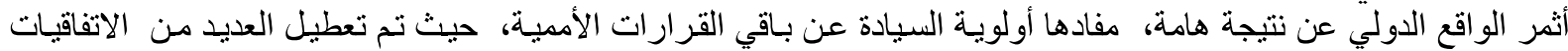

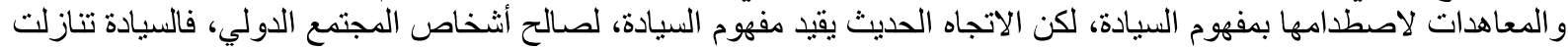

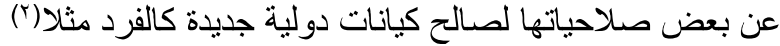

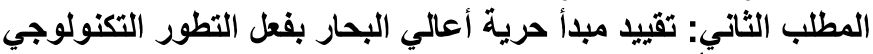

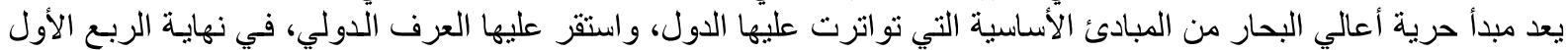

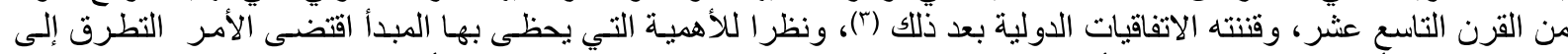

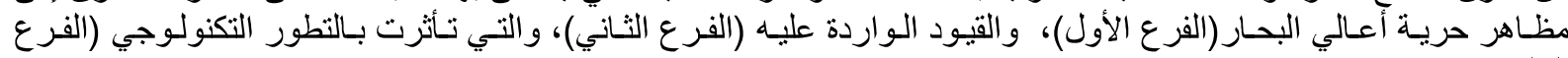

(الثالث).

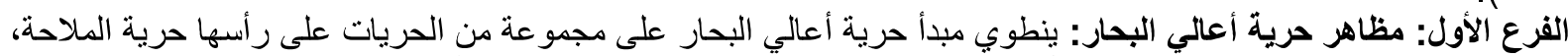

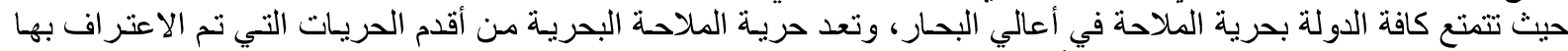

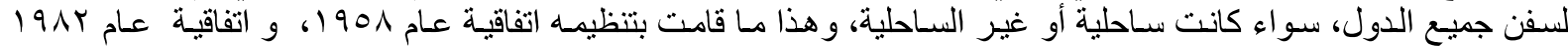

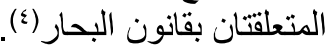

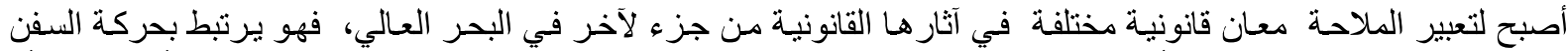

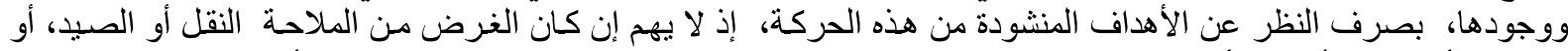

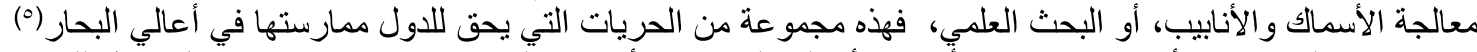

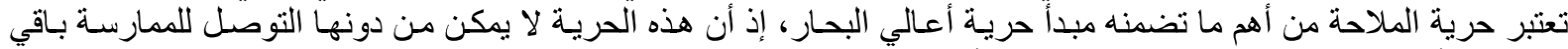

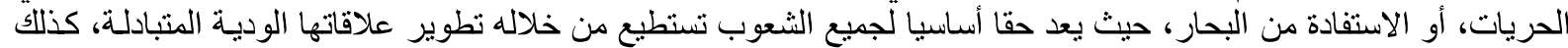

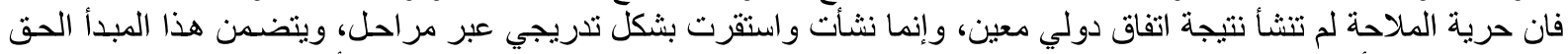

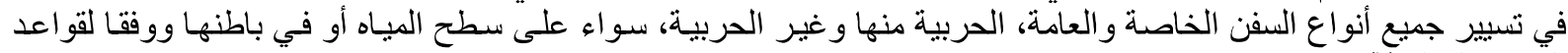

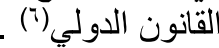

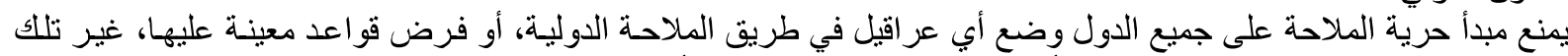

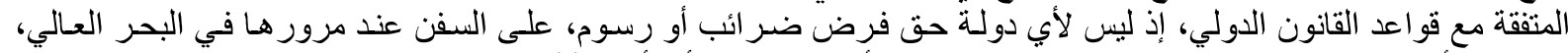

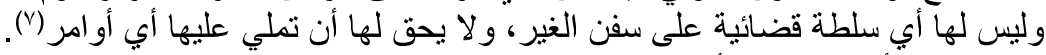

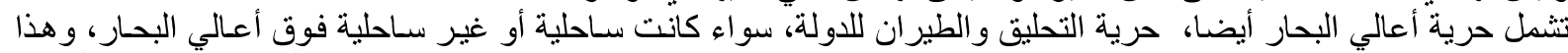

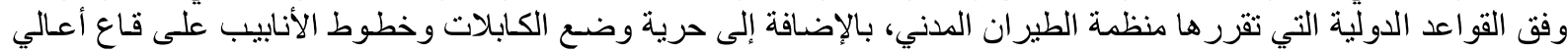

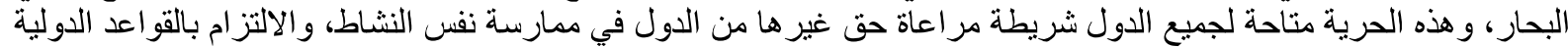

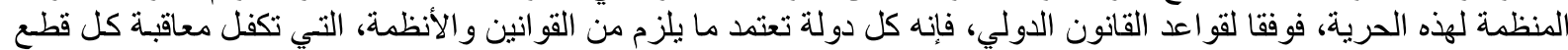

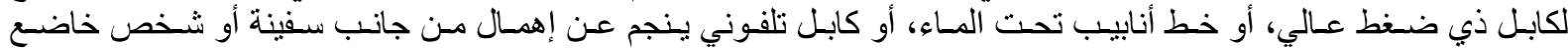

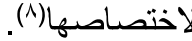

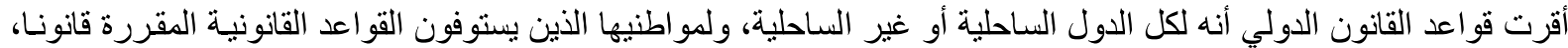

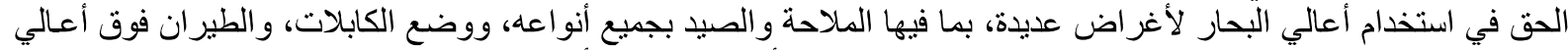

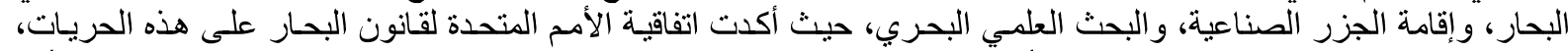

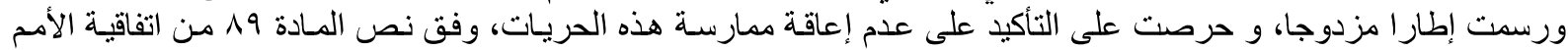

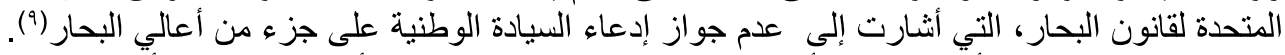

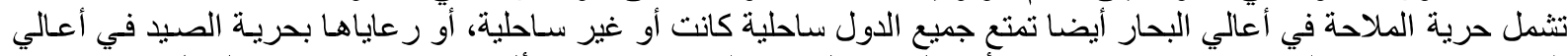

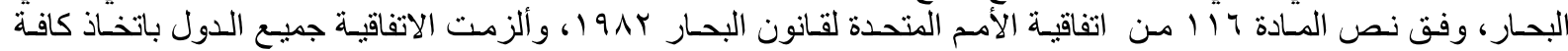

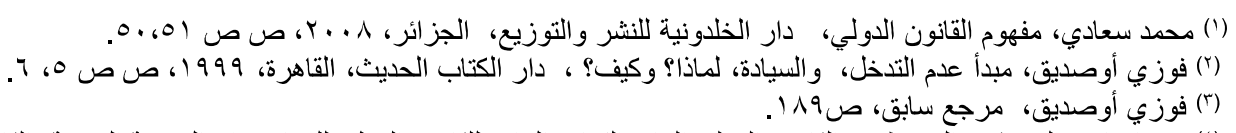

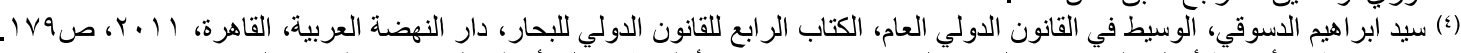

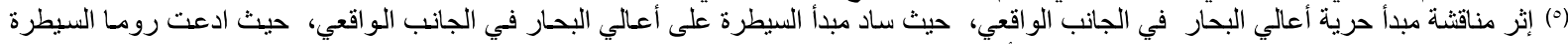

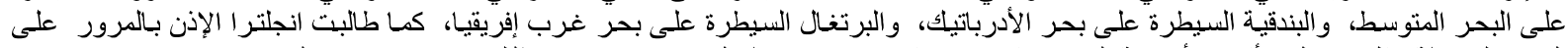

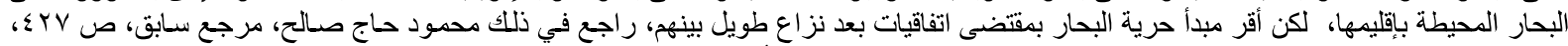

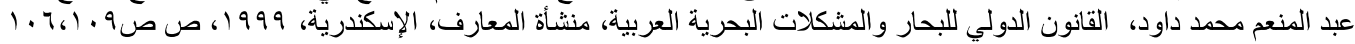

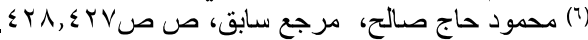

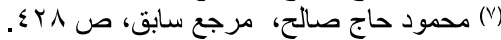

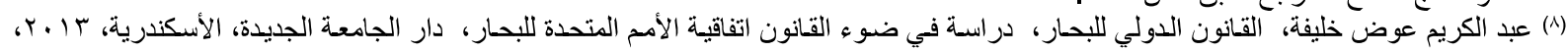

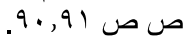

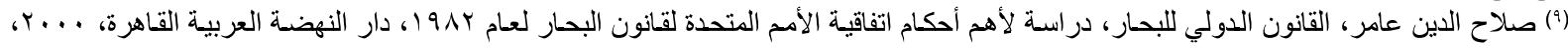

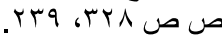


الإجراءات اللازمة للدحافظة على الثروات الحية الموجودة في أعسالي البحار، والتعاون مع الدول الأخرى لاتخـاذ الإجراءات

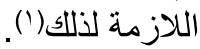

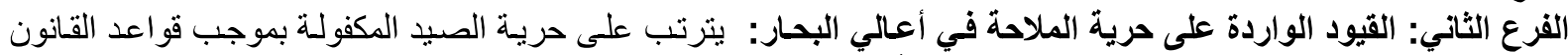

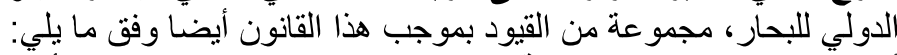

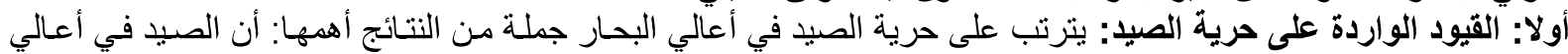

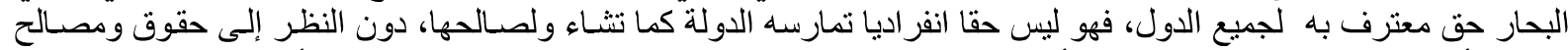

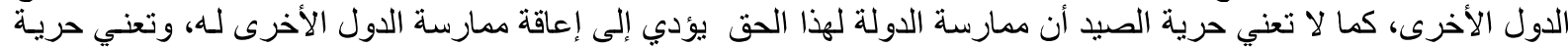

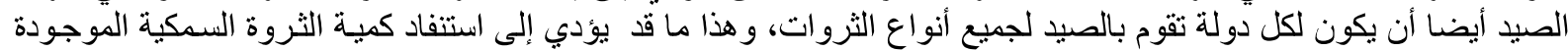

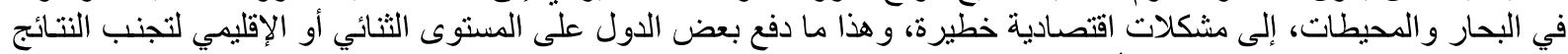

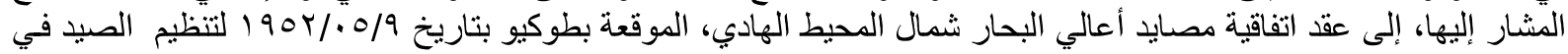

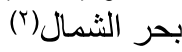

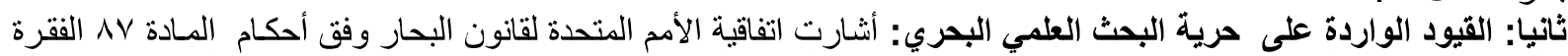

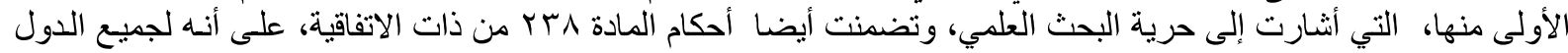

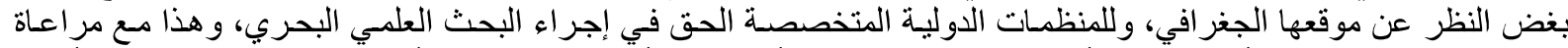

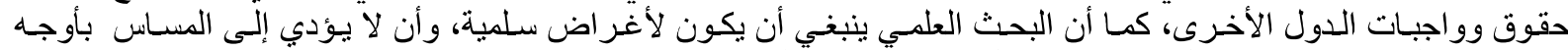

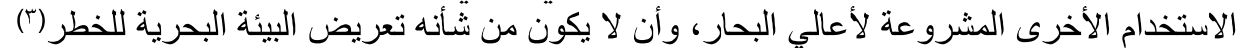

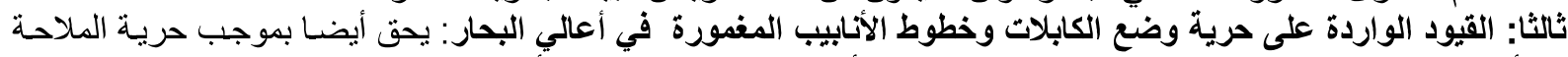

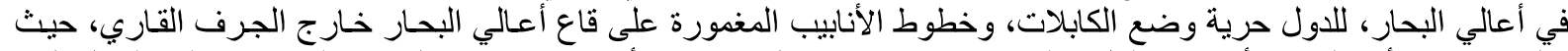

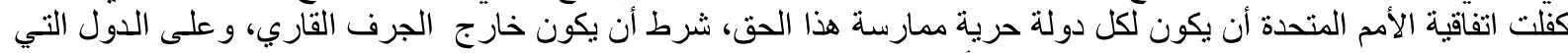

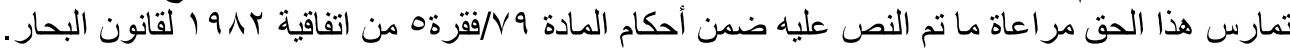

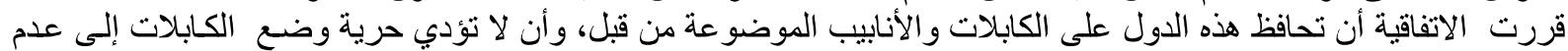

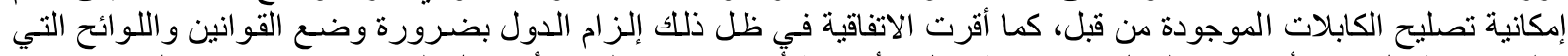

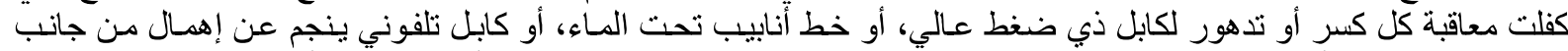

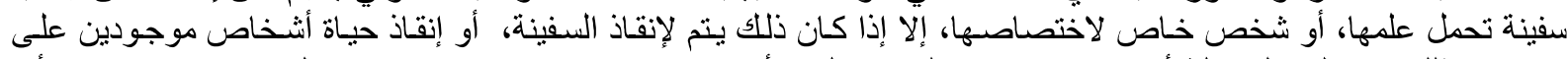

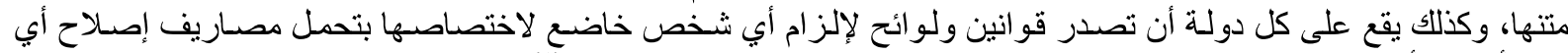

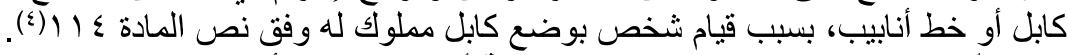

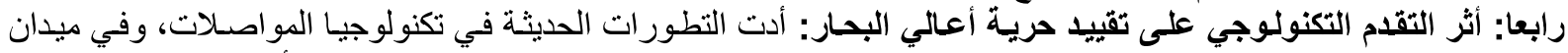

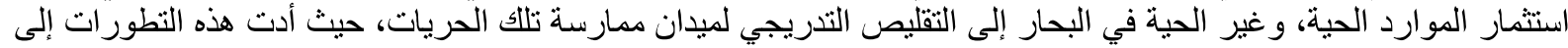

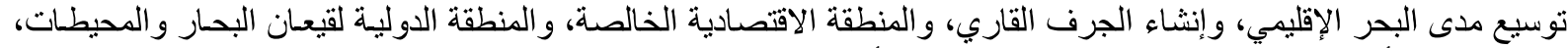

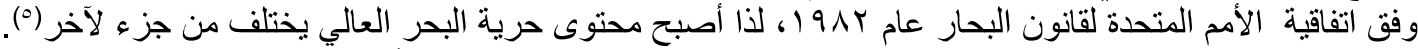

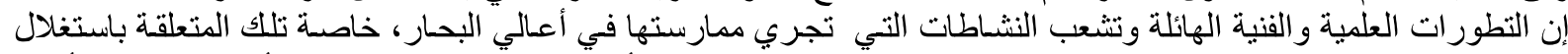

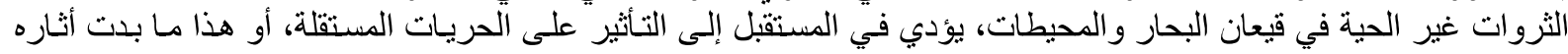

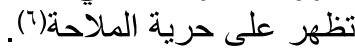
تعرض مبدأ حرية الملاحة في أعالي البحار بسبب اتساع التقدم التكنولوجي لبعض القيود منها مكافحة التلوث، وتنظيم الاستعمال

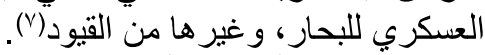

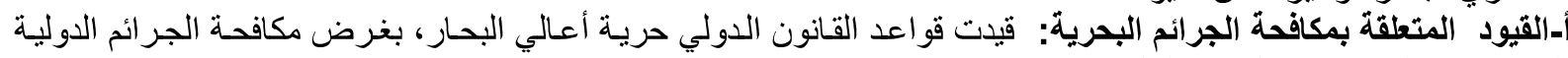

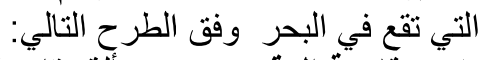

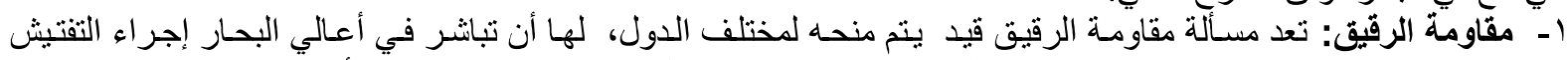

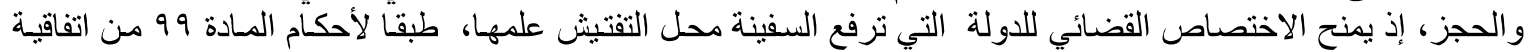

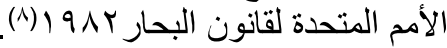

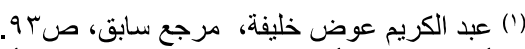

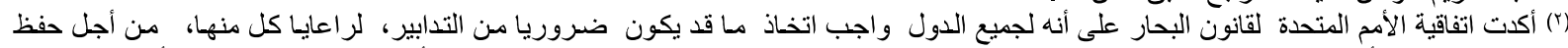

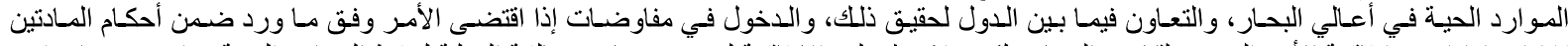

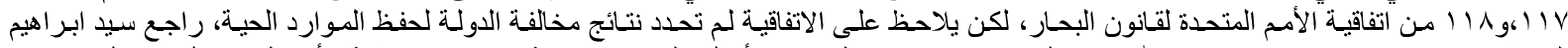

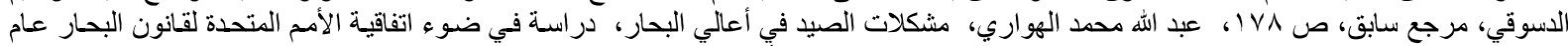

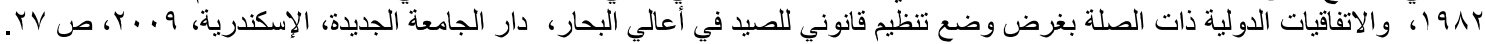

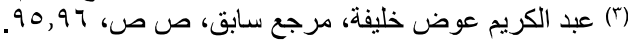

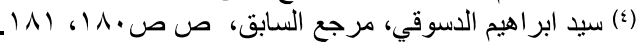

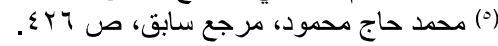

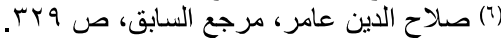

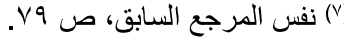

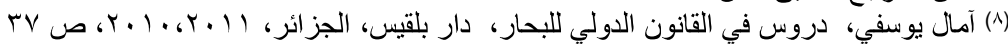




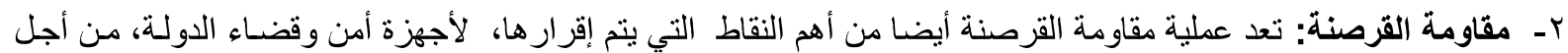

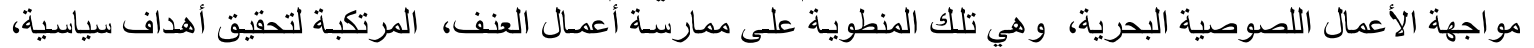

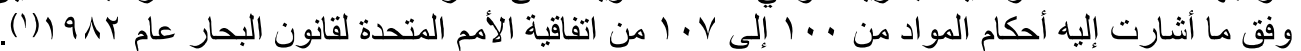

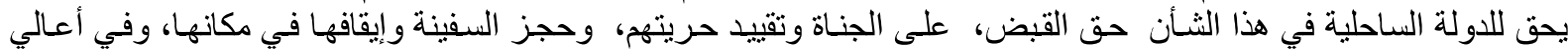

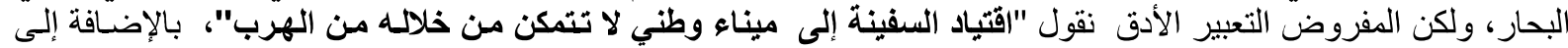

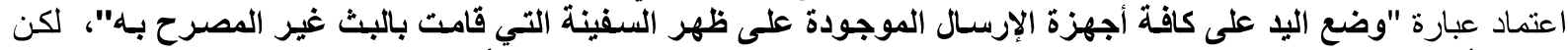

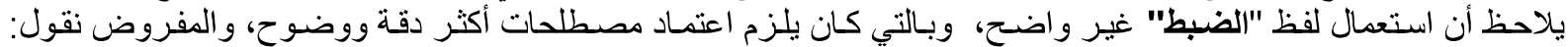

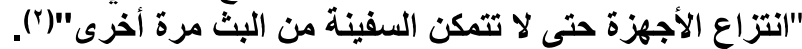

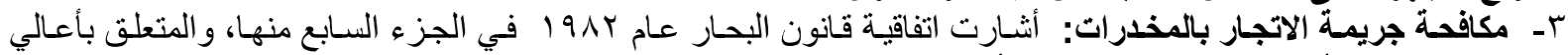

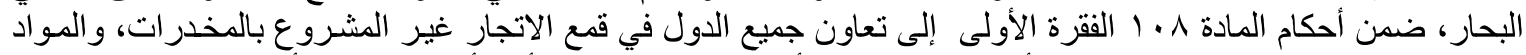

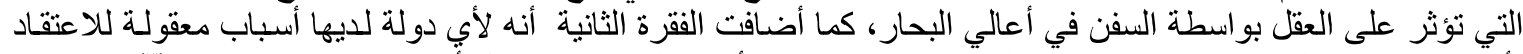

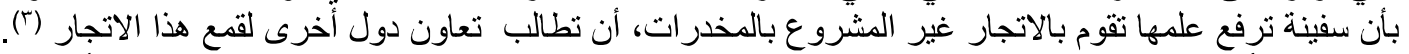

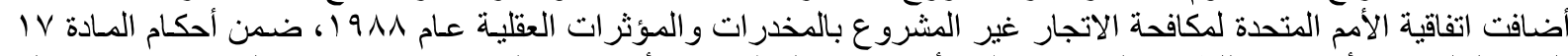

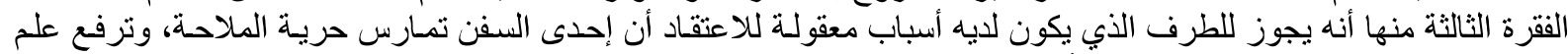

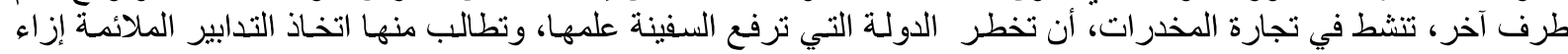

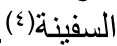

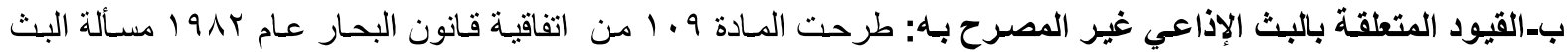

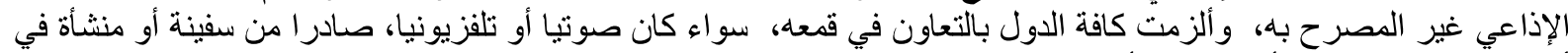

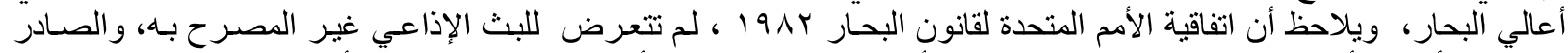

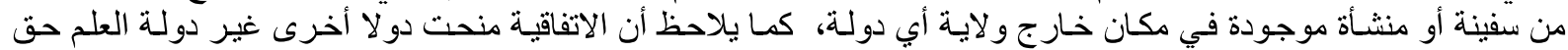

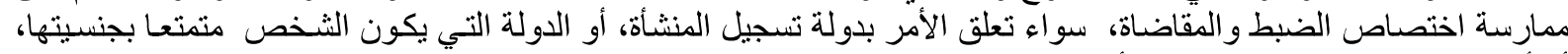

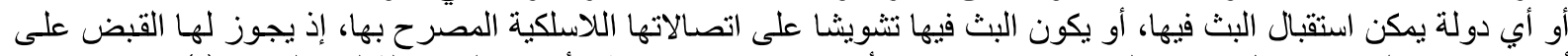

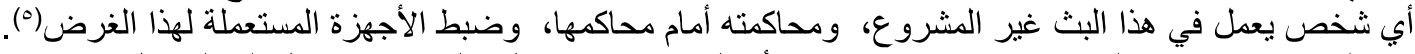

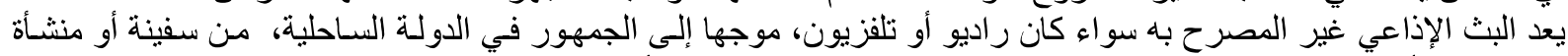

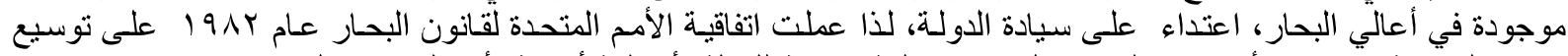

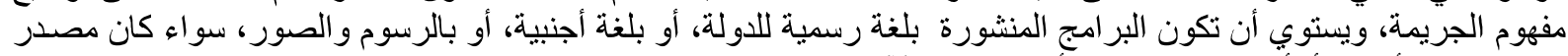

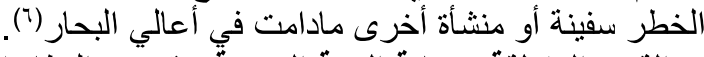

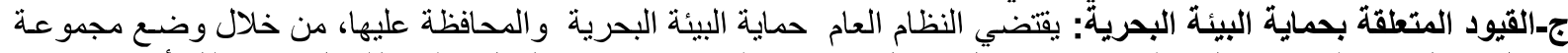

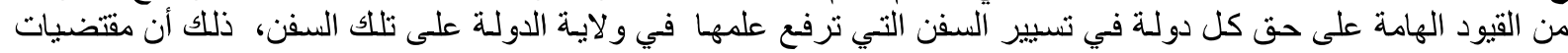

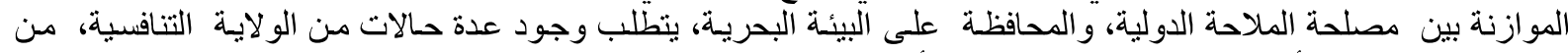

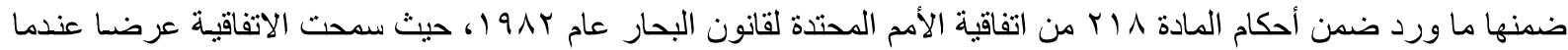

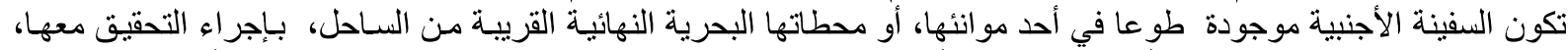

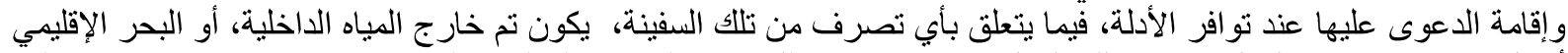

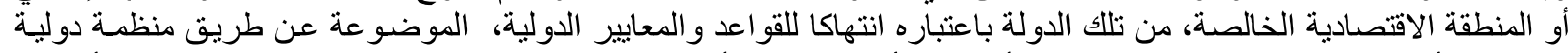

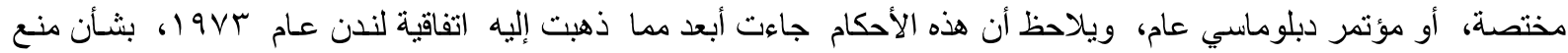

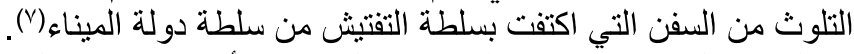

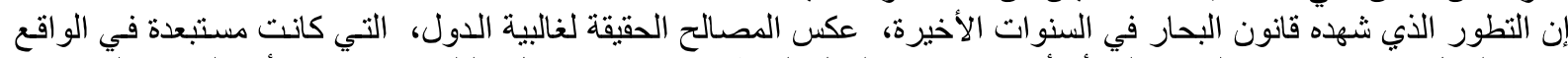

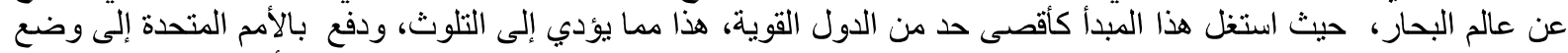

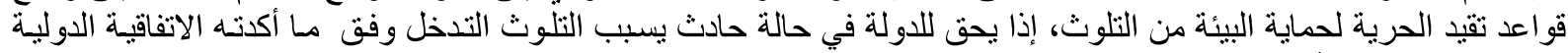

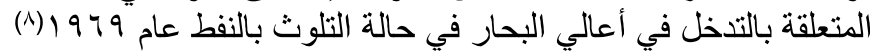

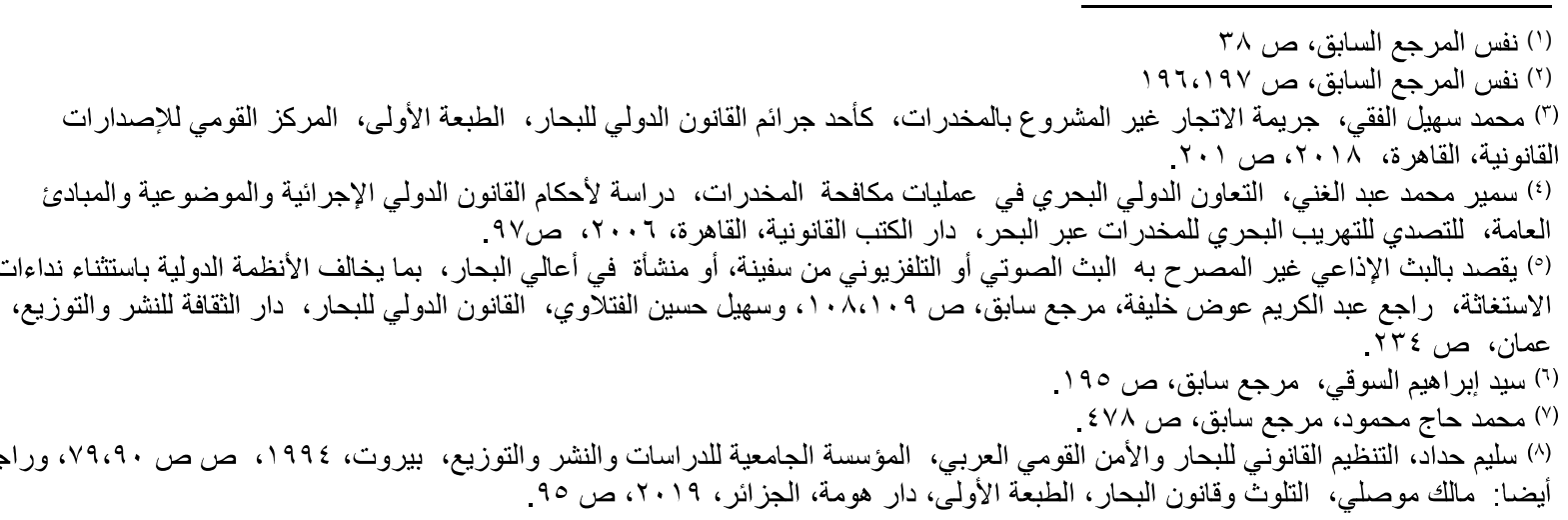




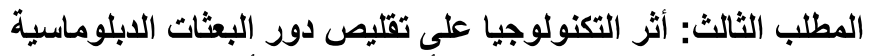

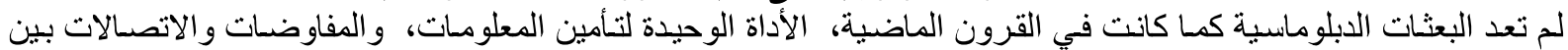

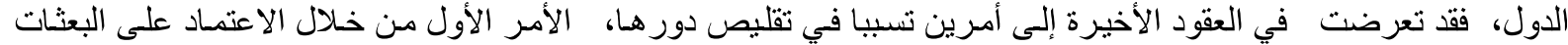

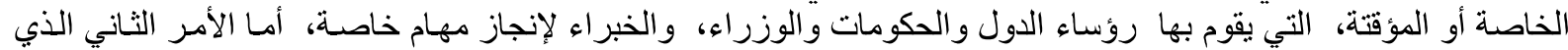

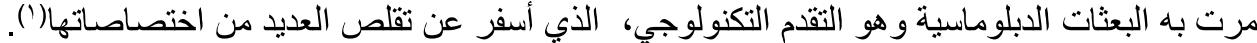

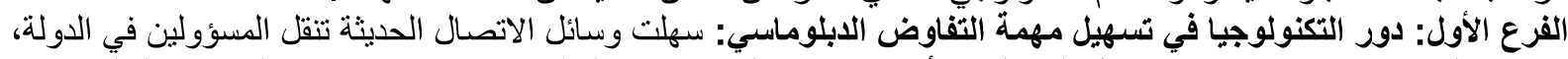

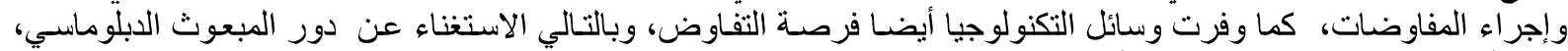

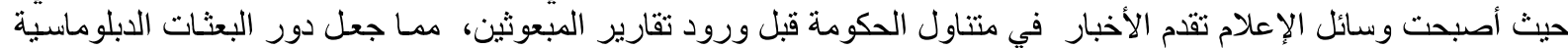

في تضاءل(r).

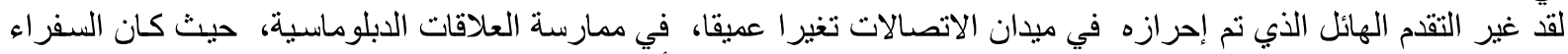

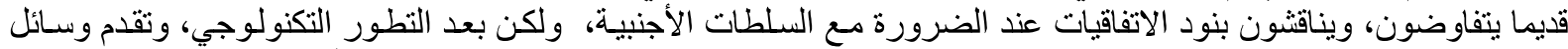

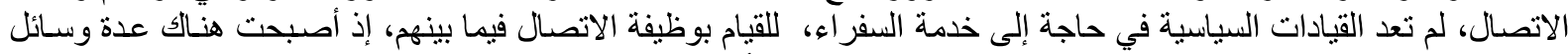

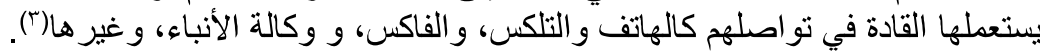

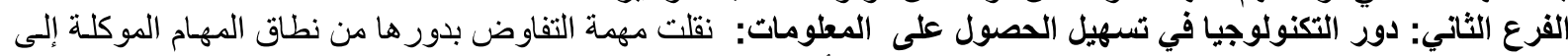

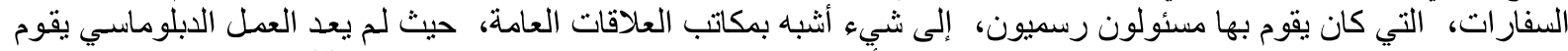

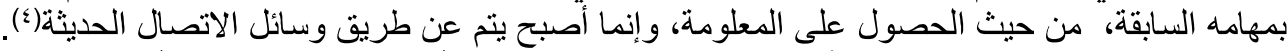

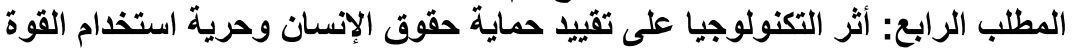

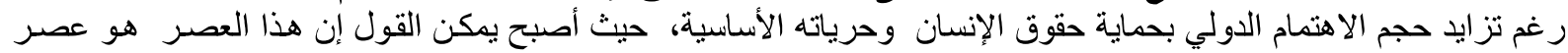

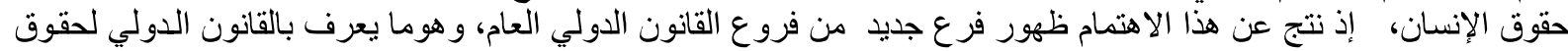

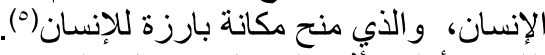

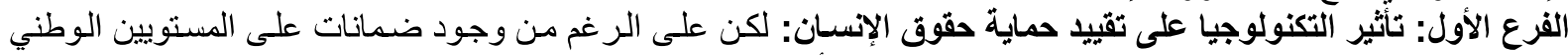

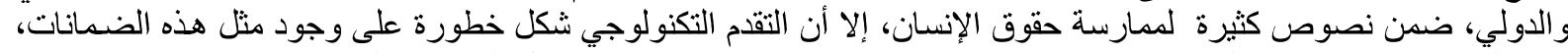

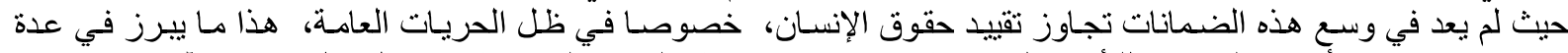

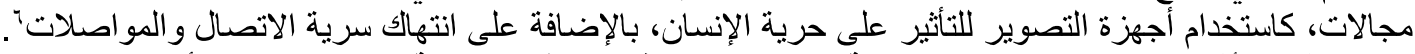

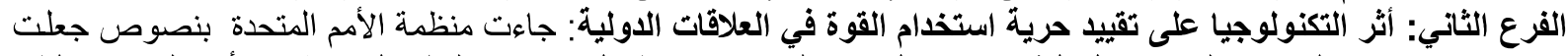

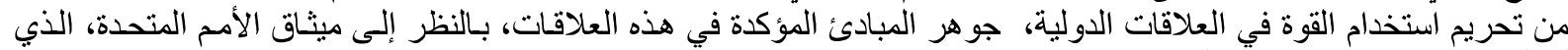

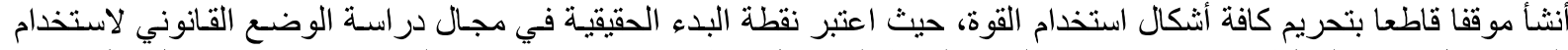

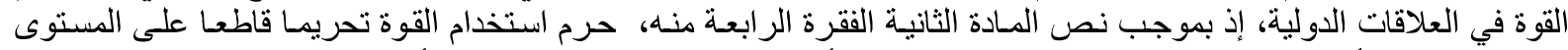

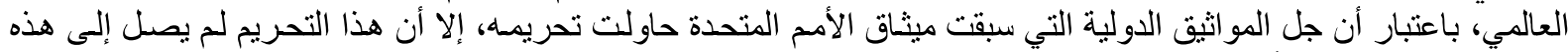

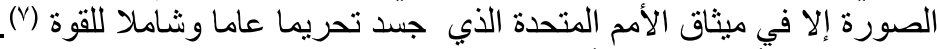

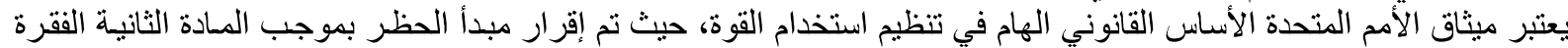

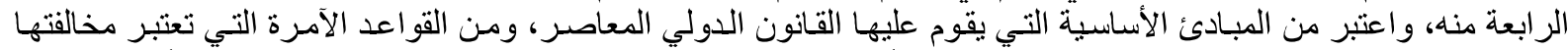

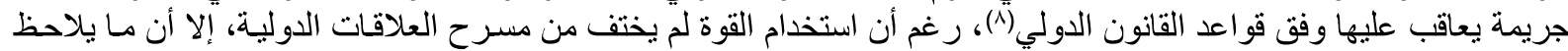

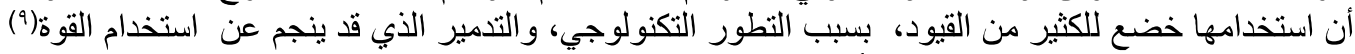

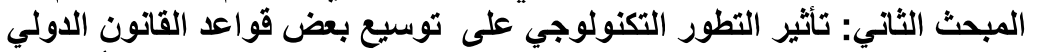

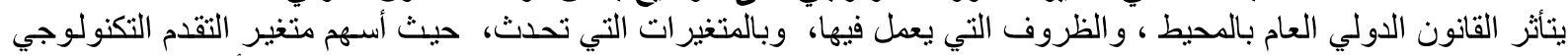

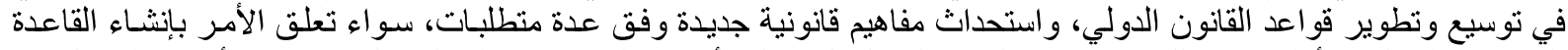

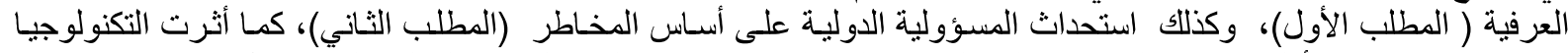

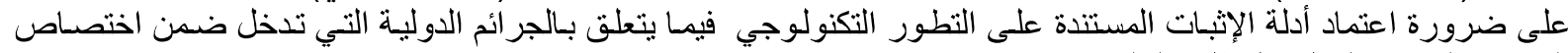
المحكمة الجنائية الدولية(الدطلب الثنالث).

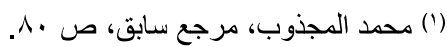

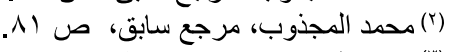

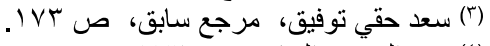

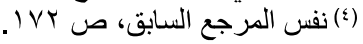

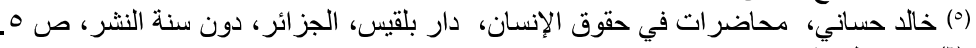

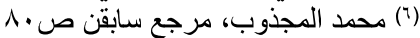

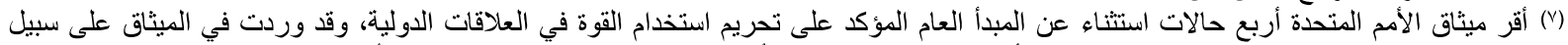

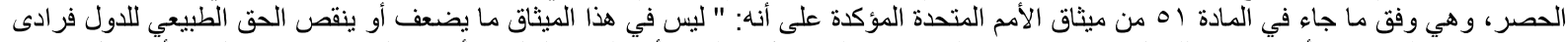

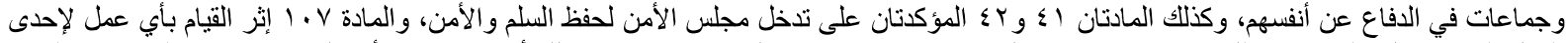

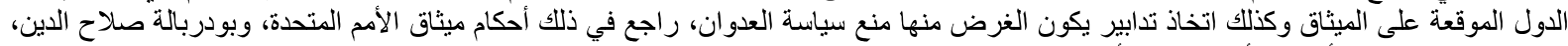

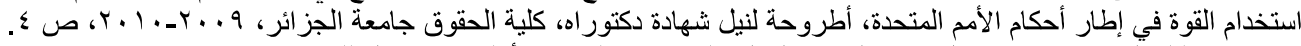

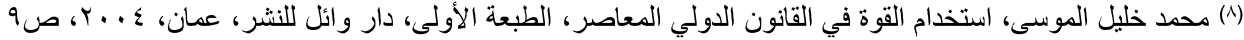

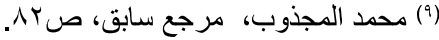




\section{المطلب الأول: أثر التكنولوجيا على الفترة المطلوبة لإنشاء القاعدة العرفية الدولية}

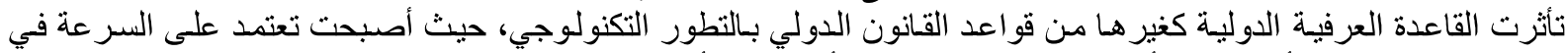

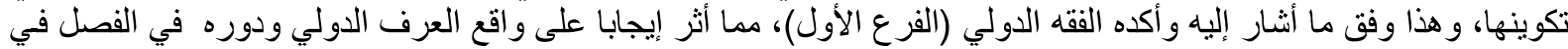
القضايا الدولية (الفرع الثاني).

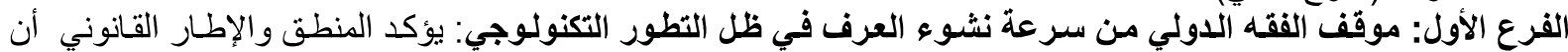

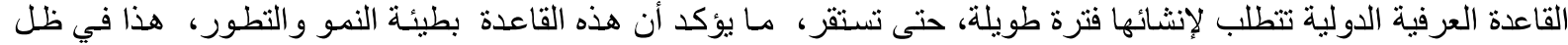

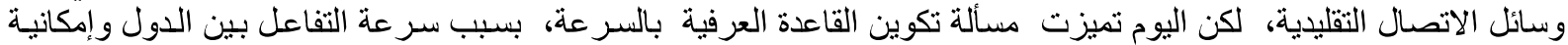

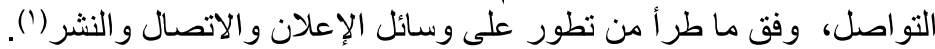

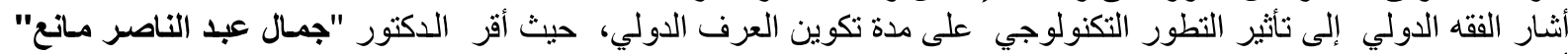

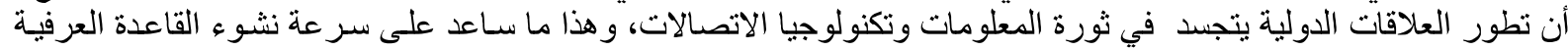

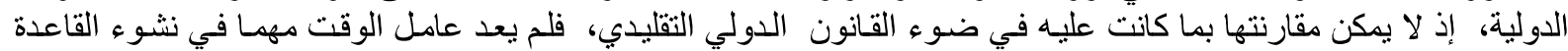

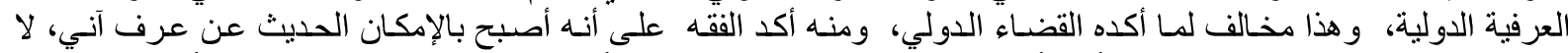

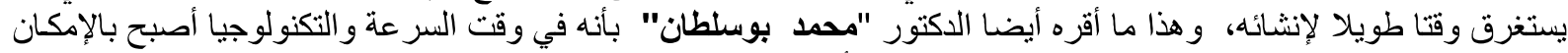

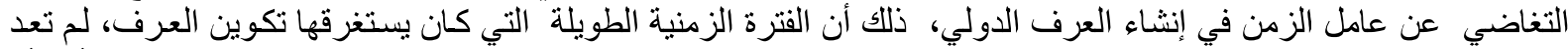

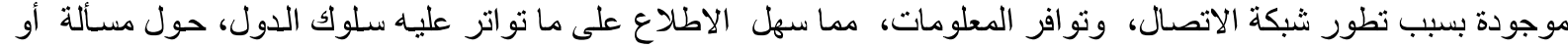

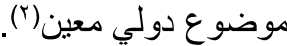

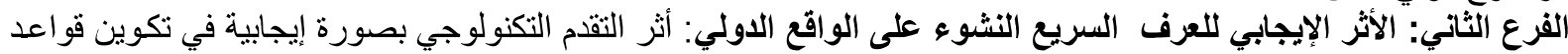

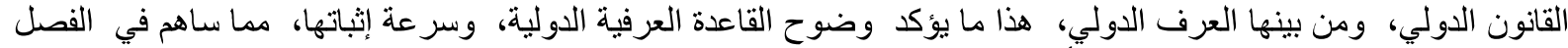

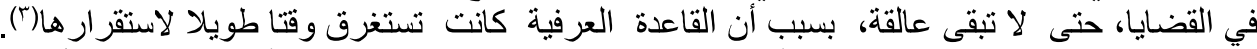

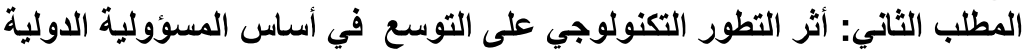

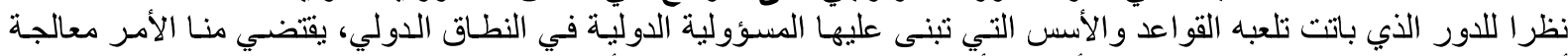

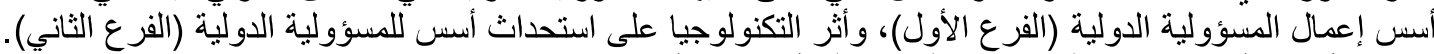

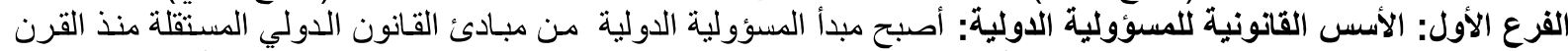

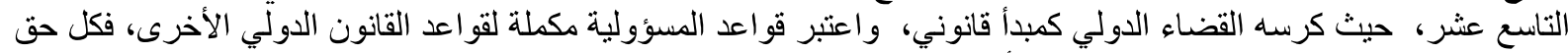

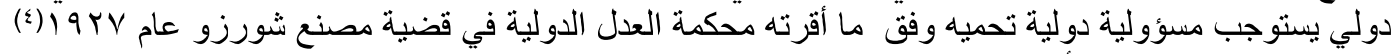

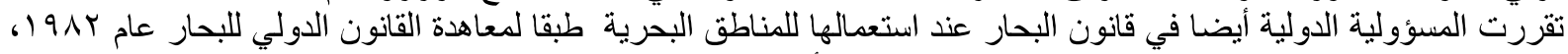

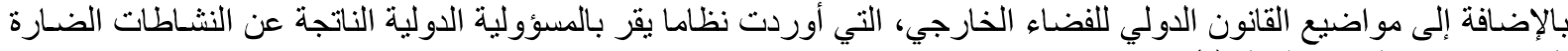

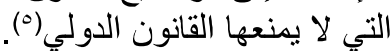

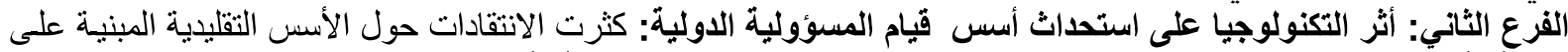

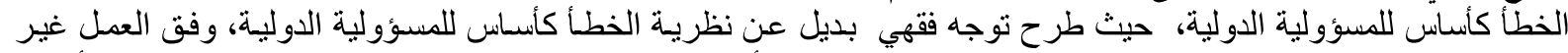

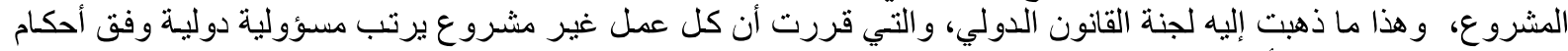

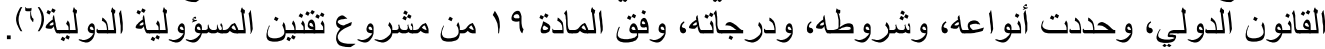

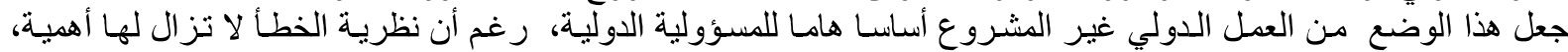

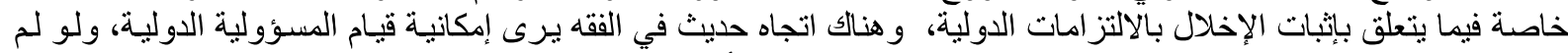

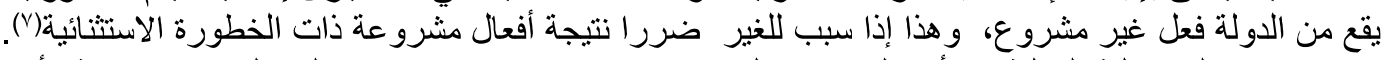

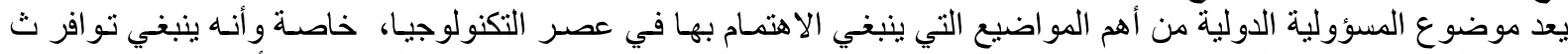

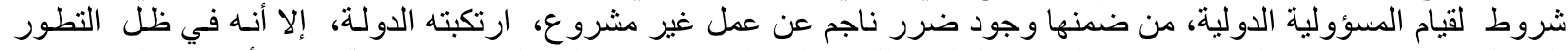

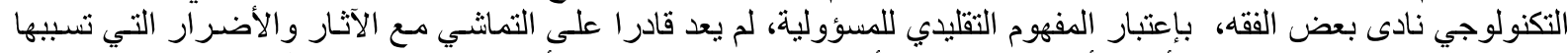

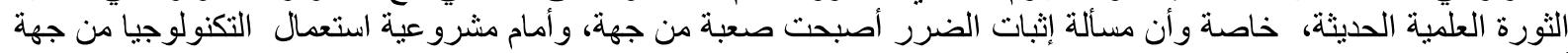

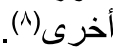

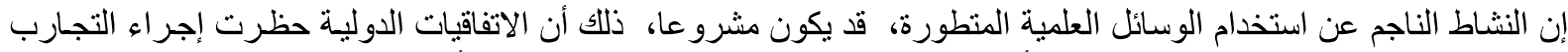

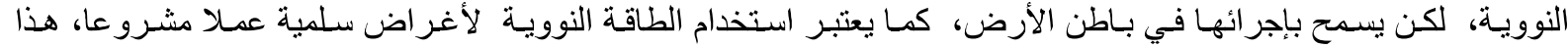
بالإضافة إلى الفضاء الخارجي الذي قد يتسبب النشاط فيه إحداث ضرر اللبشر (9).

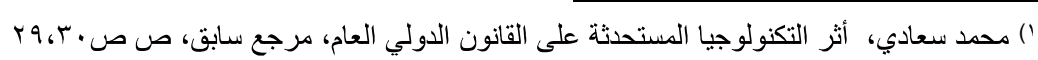

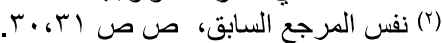

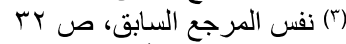

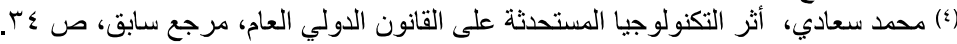

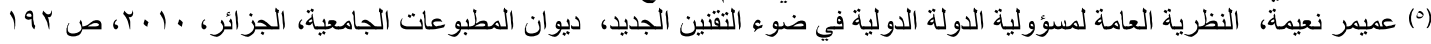

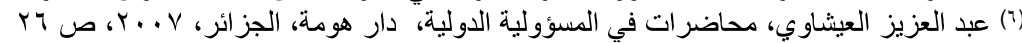

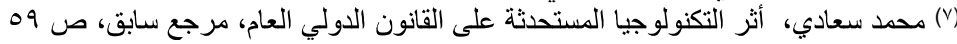

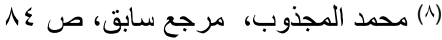

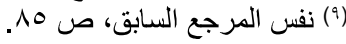




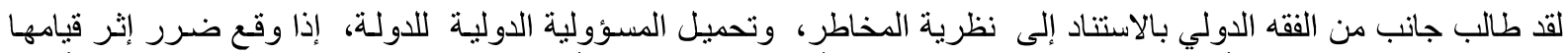

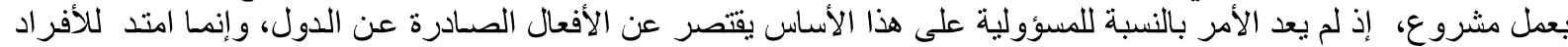

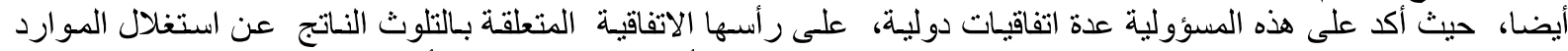

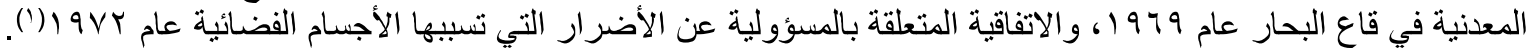

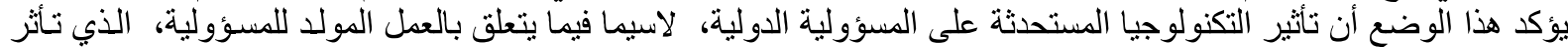

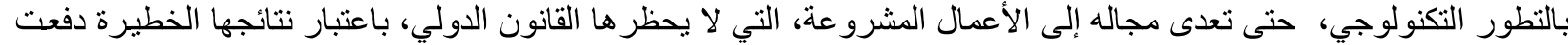

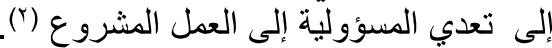

المطلب الثالث: استخدام الوسائل التكنولوجية كأداة لإثبات الجرائم الدولية

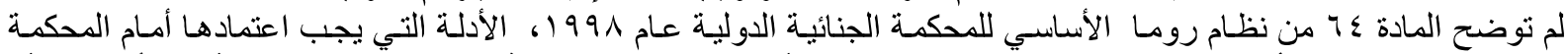

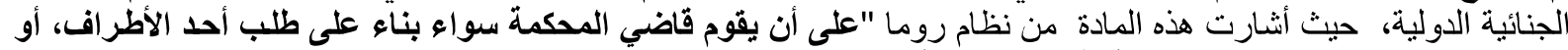

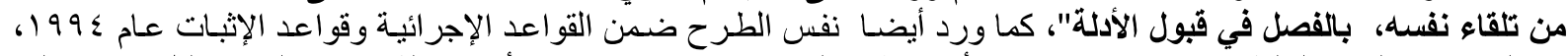

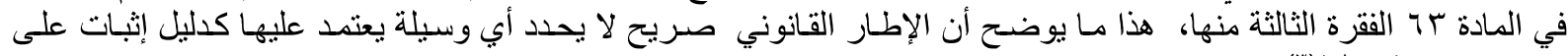

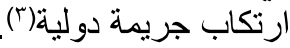

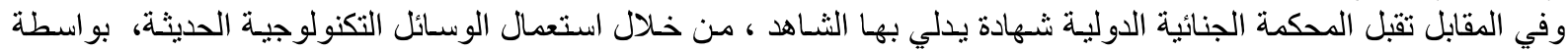
تكنولوجيا الاتصال المرئي والسمعي، بشرط أن تسمح التكنولوجيا باستجواب الثاهد من قبل المدعي العام والدفاع وقت إدلائـه

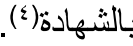

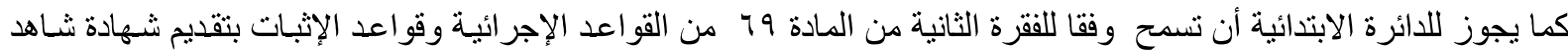

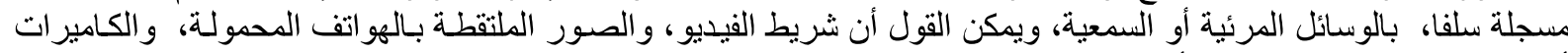

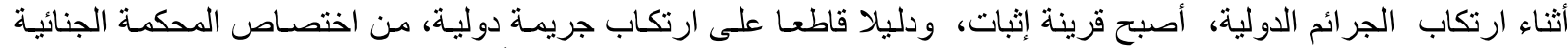

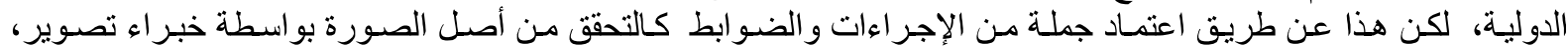

المطلب الرابع: أثر التطور التكنولوجي على التراث المشترك للإنسانية

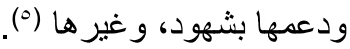

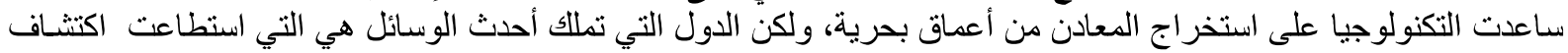

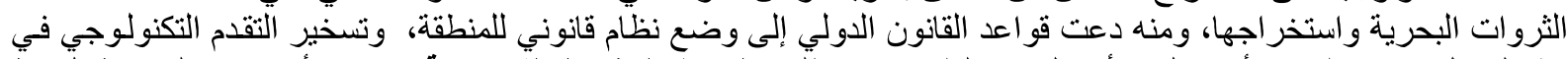

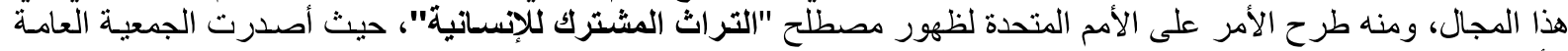

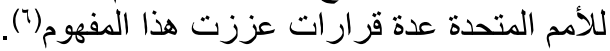

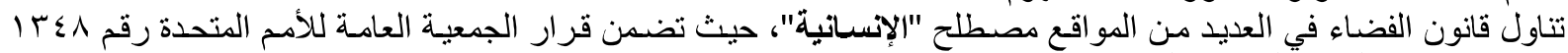

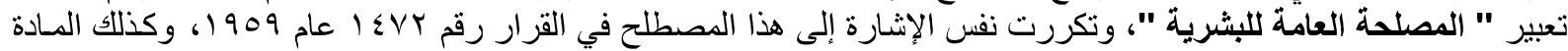

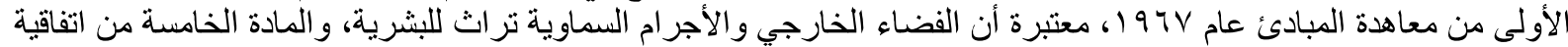

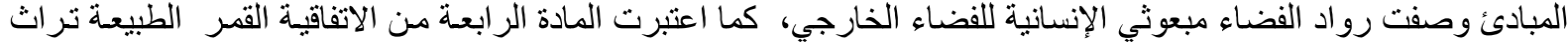

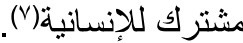

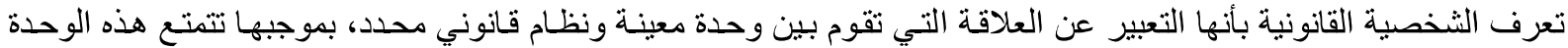

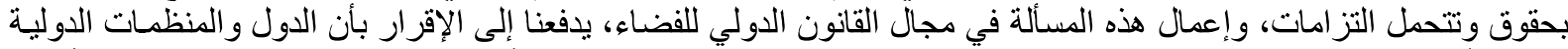

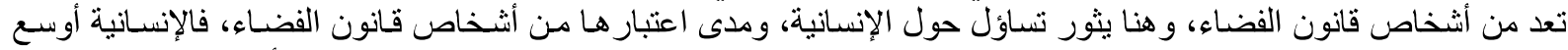

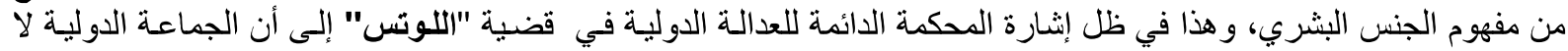

تتكون إلا من دولة) (^).

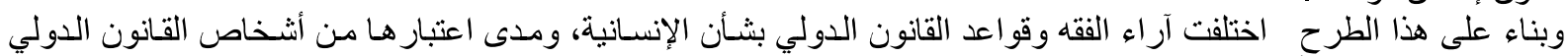

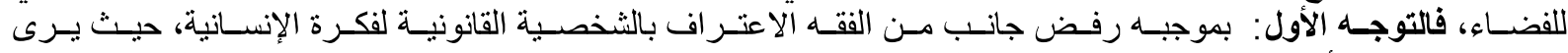

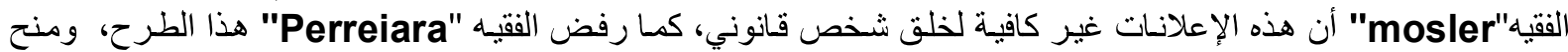

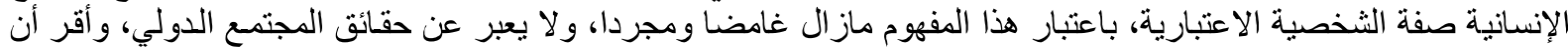

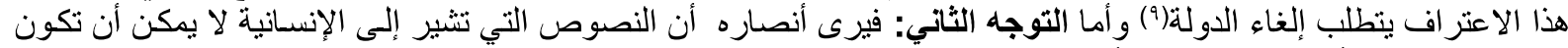

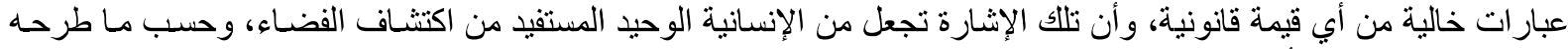
الفقيه "Williams" أن وثائق قانون الفضاء واضحة وانية، وكافية، وصريحة، ودقيقة في جعلها من البشرية المستفيد من الفضـاء،

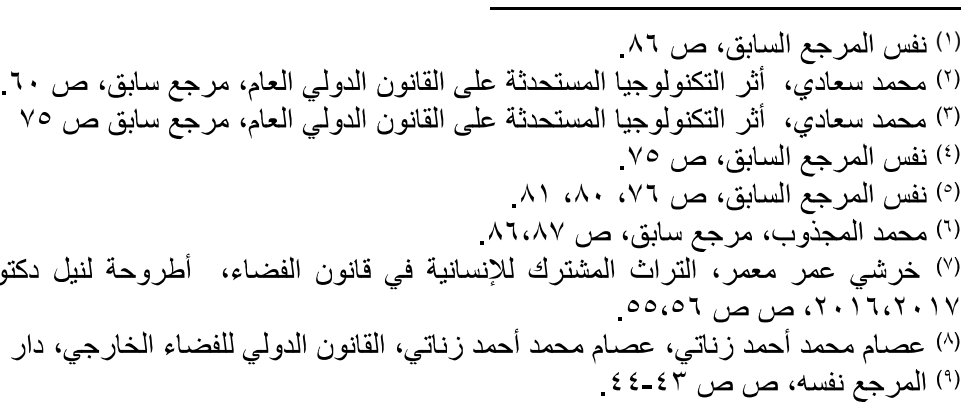


كما أكد الفقيه "Marcoff" أن البشرية مخاطبة مباثرة بقواعد قانون الفضاء، ولكن هذا الفقيه يعتبر البشرية شخصا سلبيا يتلقى خاتمة

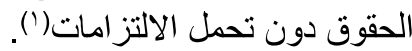

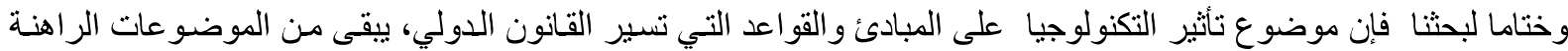

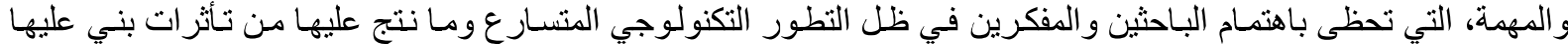

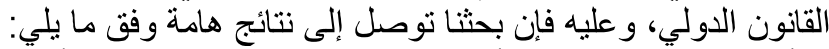

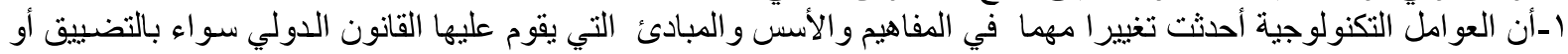
التقييد.

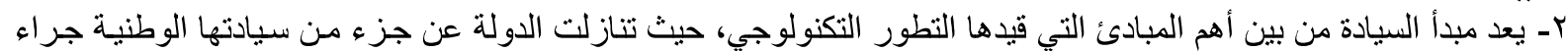

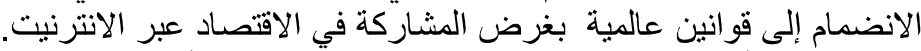

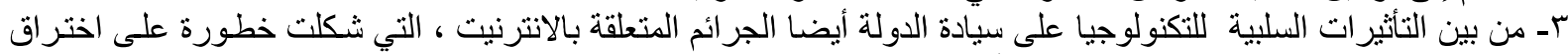

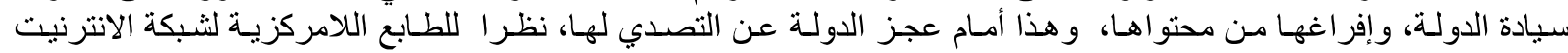

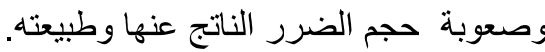

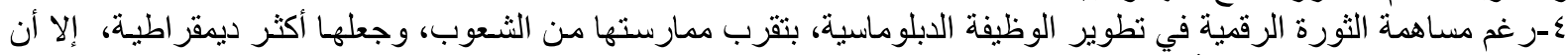

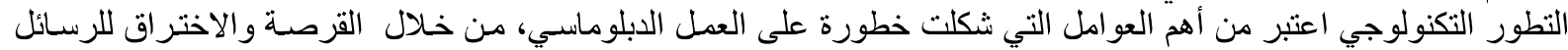

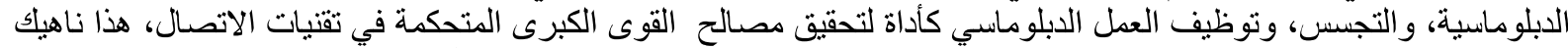

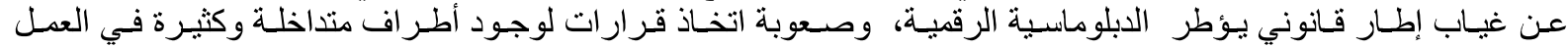
الدبلوماسي. هـ إذا كانت أعالي البحار مفتوحة لجميع الدول ساحلية كانت أو غير سـاحلية، فإن هذه الحرية تخضع لضوابط وقيود تهدف

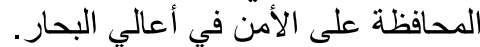

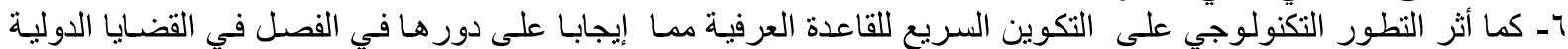

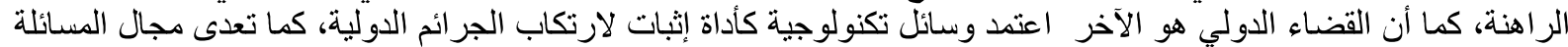

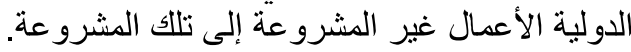

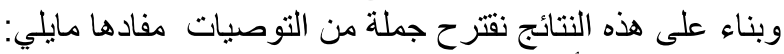

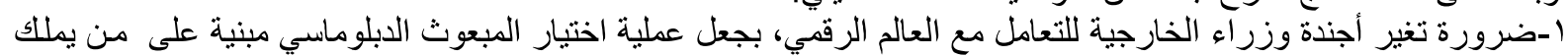

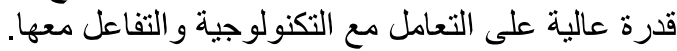

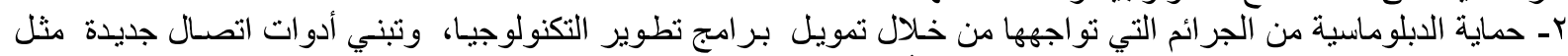

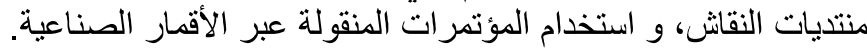

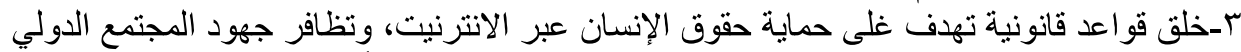

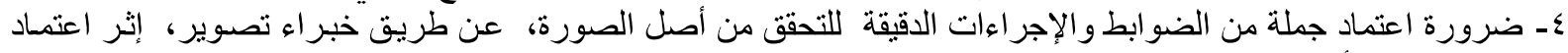
الدليل الإلكتروني أمام القضاء الدونة الدولي.

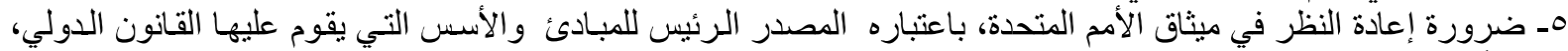

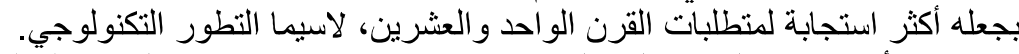

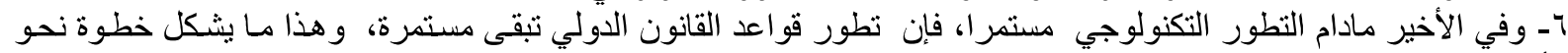

\section{قائمة المراجع} الأمام تبحث عنها الدول لترقية مسيرتهاً وتطلعاتها.

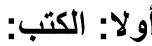

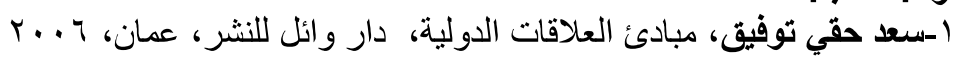

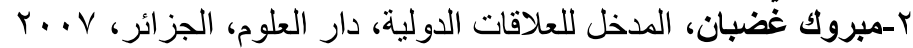

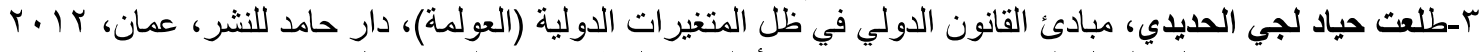

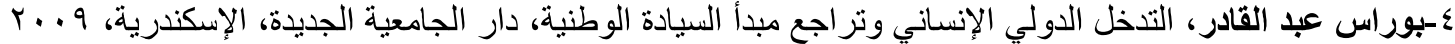

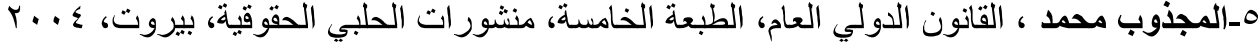

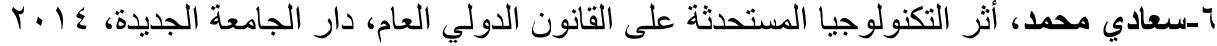

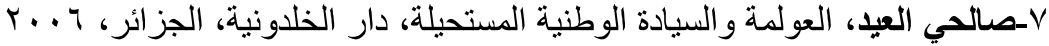

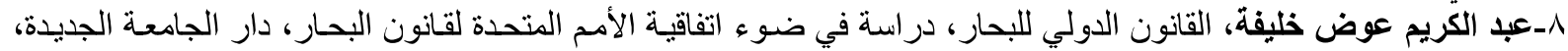

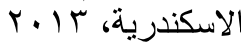

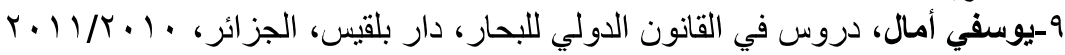

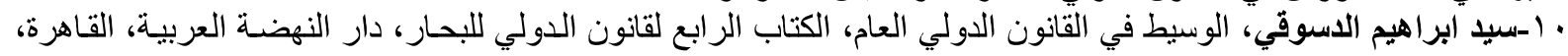




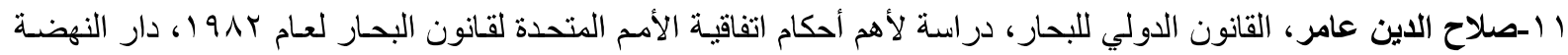

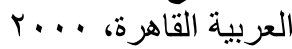

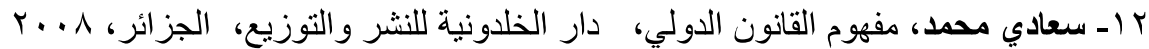

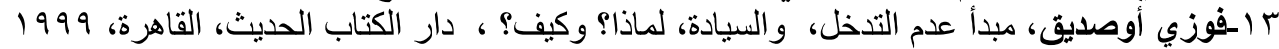

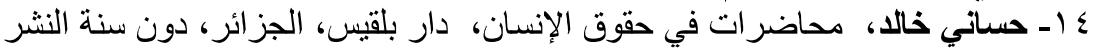

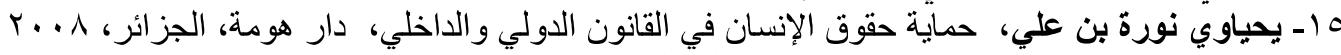

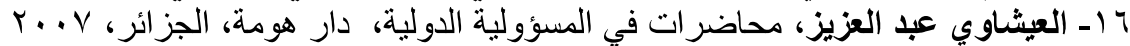

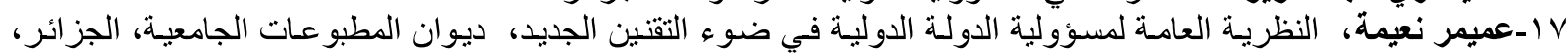

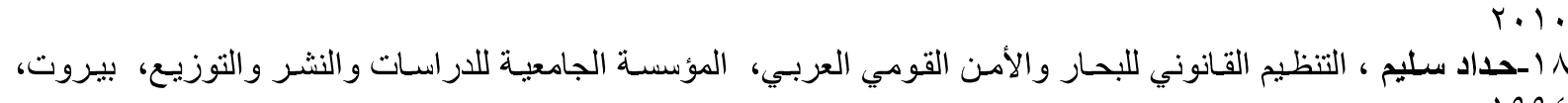

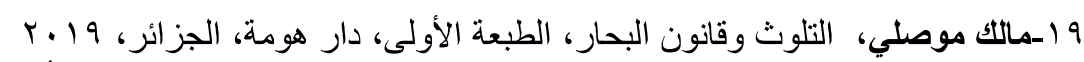

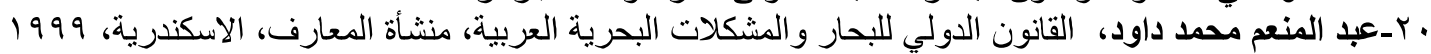

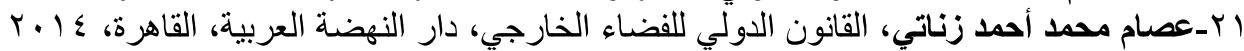

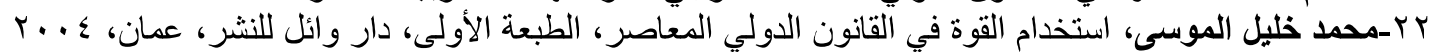

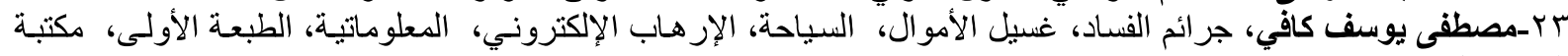

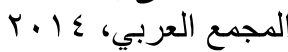

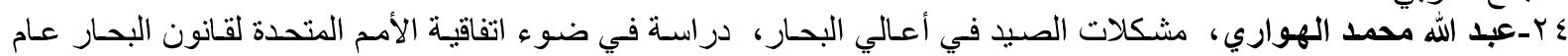

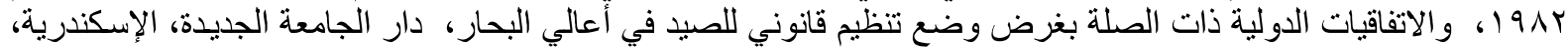
$r+.9$

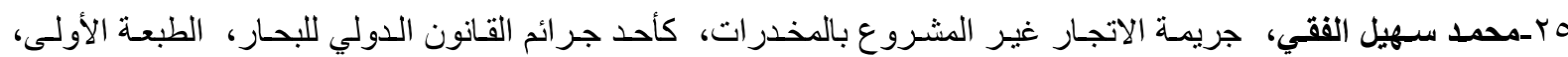

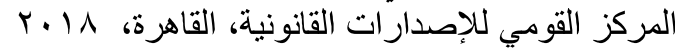

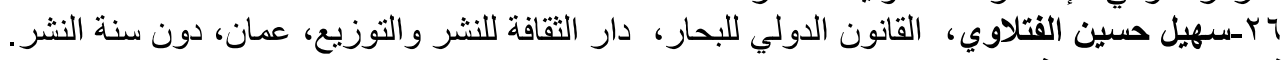

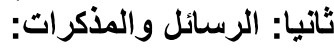

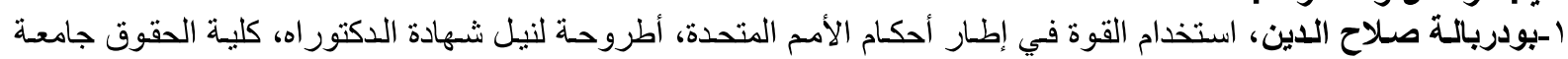

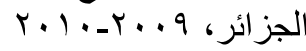

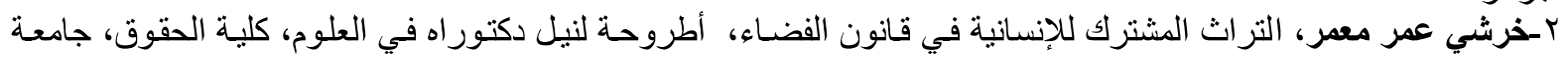

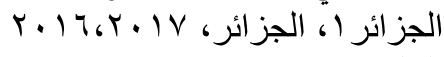

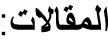
ا -فائز ذنون جاسم، تأثير الانترنيت على السيادة،دون دار النشر،ودون سنة النشر

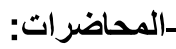

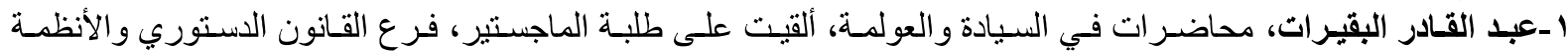

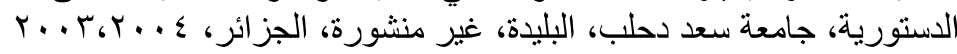

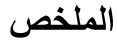

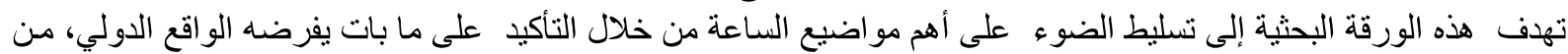

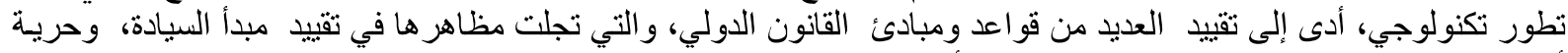

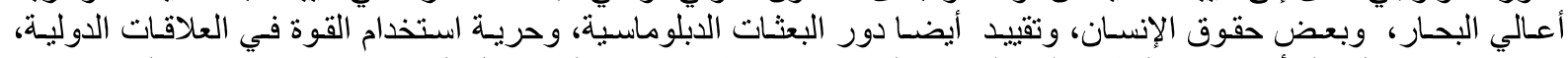

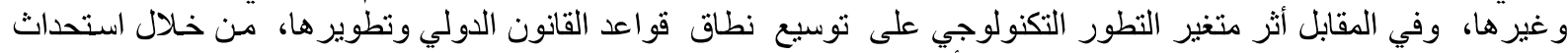

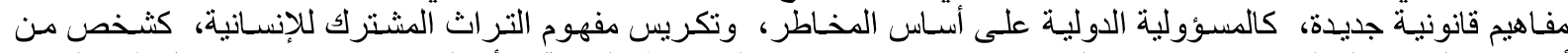

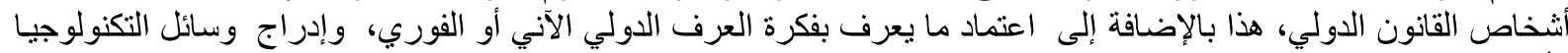

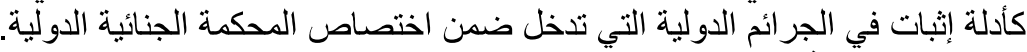
الكلمات المفتاحية: التطور التكنولئوجي، مبادئ القانون الدولي، السيادة، المسؤولية الدولية، الدية، العرف الدولي، حريـة أعالي

\section{Abstract}

البحار.

The aim of thispaperis to highlight the mosttopical issues of the day by emphasizing the technologicalevolution of international law, which has led to restrictions on a number of rules and principles of international law, in particular the principle of sovereignty, freedom of the high seas and certain humanrights، The restriction also of the role of diplomatic missions, the freedom to use force in international relations, etc., and on the other hand the changing impact of technology on the expansion and development of the rules of international lawthrough the introduction of new legal concepts, such as risk-based international responsibility and the establishment of the concept of the commonheritage of 
mankind as a subject of international law, This is in addition to the adoption of the socalled notion of immediate or immediate international custom and the inclusion of the means of technology as evidence in international crimes fallingunder the jurisdiction of the International Criminal Court.

Keywords : Technological devlopment, principales of international Law, sovereignty, international responsibility, international custom, freedom of the high seas. 